\title{
Extreme Asymmetric Volatility, Leverage, Feedback and Asset Prices
}

\author{
Sofiane Aboura \\ Université de Paris Dauphine, DRM-Finance, France \\ Niklas Wagner \\ Passau University, Germany
}

Version: February 2009

The authors would like to thank participants at the International Symposium on Advances in Financial Forecasting, the 3rd Annual Risk Management Conference, Singapore, and seminar participants at Dauphine and Hannover for their valuable comments. The paper benefited from very helpful discussions with Eric Gilleland, Ser-Huang Poon and George Tauchen. Part of the paper was written while the first author was visiting Leibniz University, Hannover. All errors remain with the authors. Corresponding author: Niklas Wagner, Department of Business and Economics, Passau University, 94032 Passau, Germany, E-mail: nwagner@alum.calberkeley.org. 


\begin{abstract}
Asymmetric volatility in equity markets has been widely documented in finance, where two competing explanations, as considered in Bekaert and $\mathrm{Wu}$ (2000), are the financial leverage and the volatility feedback hypothesis. We explicitly test for the role of both hypotheses in explaining extreme daily U.S. equity market movements during the period January 1990 to September 2008. To this aim, we examine asymmetric volatility based on a novel model of market returns, conditional market volatility and volatility of volatility. We then test for extreme asymmetry and the distinct predictions of both hypotheses. Our results document significant extreme asymmetric volatility. This effect is contemporaneous, consistent with both hypotheses, and it is important for large market declines. We further point out aggregate asset pricing implications under extreme volatility feedback.
\end{abstract}

Key Words: market volatility, asymmetric volatility, leverage effect, volatility feedback, VIX, market stress

JEL Classification: C32, G10, G32 
Asymmetric volatility in equity markets has been widely documented in finance, stating that returns and volatility are negatively related and that this relation is more pronounced for negative returns. In other words, large volatility increases and large market declines tend to coincide. This striking phenomenon is relevant to financial stability and to the occurrence of periods of market stress (see for example IMF (2003)). It may also affect the overall economy, as the following foresighted statement illustrates: "Members of the Federal Reserve's policy-setting committee worried at their most recent meeting that housing and financial market stress could trigger a nasty slide in the economy. (Reuters, April 8, 2008)". Asymmetric equity market volatility is important for at least three reasons. First, it is an important characteristic of the market volatility dynamics, has asset pricing implications and is a characteristic of priced risk factors. Hence, it is important in the determination of time-varying market risk premia. Second, it plays an important role in risk prediction, hedging and option pricing. Finally, asymmetric volatility implies negatively skewed return distributions, i.e. it may help to explain some of the probability of market value losses. Two prominent competing economic hypotheses, which aim at an explanation of the phenomenon, are the so-called "leverage effect" hypothesis and the "volatility feedback effect" hypothesis; see Black (1976), Campbell and Hentschel (1992) and Bekaert and $\mathrm{Wu}$ (2000). While it is known that volatility changes behave asymmetrically with security price changes, it is not yet documented whether such behavior may also be considered as a driver of periods of market stress. Campbell and Hentschel (1992) point out that volatility feedback is presumably more important during periods of market stress. Therefore, the phenomenon may help to explain the severity of large market declines. Their results are based on a model of autoregressive conditional heteroskedasticity $(\mathrm{ARCH})$, which is not designed to model extreme behavior. Hence, it remains an open question whether the asymmetric price-volatility relation prevails when markets face extreme downside price shocks and whether the risk of large market volatility shocks is priced.

In the present paper, we address asymmetric volatility when markets face extreme downside price movements. Our paper covers three novel areas. First, we propose a model of the distribution of market returns and observable conditional volatility. We do this for the U.S. equity market and the market volatility index (VIX), which is an observable approximation of conditional market volatility. Our model includes conditional market returns, conditional volatility as well as volatility of volatility. We allow for asymmetric volatility based on a threshold 
model of stochastic conditional volatility. Conditional volatility of volatility is modelled by an asymmetric ARCH-process. The random innovations of our model are given by a pair of unexpected return and volatility shocks. These shocks may exhibit cross-sectional dependence, which we examine in our following step.

Second, we contribute to the literature by examining volatility asymmetry under normal periods within the dynamic conditional correlation (DCC) approach of Engle (2002). For periods of market stress, we consider extreme dependence in the context of extreme value theory (EVT). We apply EVT in order to perform distinct tests of the implications of the volatility feedback hypothesis for large unexpected return and volatility shocks. The feedback hypothesis predicts that periods of pronounced volatility increases together with extreme negative returns are not simply outlying observations. In contrast, they should be systematically dependent. While market volatility is heavily subject to jump risk (see e.g. Todorov and Tauchen (2008)), volatility feedback is known to potentially amplify large negative return shocks (see Campbell and Hentschel (1992)). In sum, when volatility feedback is at work, volatility jumps and large negative return shocks amplify each other. This could lead to a situation, where the market would be predicted to melt down given a large initial positive shock to volatility. We empirically examine the possibility of such an extreme event, which is a component to systemic market risk.

Finally, we contribute to the empirical asset pricing literature by outlining pricing implications of extreme volatility feedback. As pointed out for example in Li (2004) and Engle and Mistry (2007), intertemporal asset pricing models predict volatility asymmetry once market volatility is a priced risk factor. We consider the empirical asset pricing implications of extreme volatility feedback in more detail.

Our daily sample covers daily U.S. market returns and VIX volatility during the period 1990 to 2008. It includes several periods of market stress, including the ongoing financial crisis. For the univariate series, our empirical results indicate a statistically insignificant leverage effect, i.e. lagged market returns do not significantly affect VIX volatility. However, we find a significant hyper-level leverage effect. Given this latter effect, volatility of volatility is asymmetric in the sense that past positive volatility shocks drive positive shocks to volatility of volatility. Our empirical findings on the dependence of unexpected return and volatility shocks further documents that time-variation is an important characteristic of asymmetric market volatility. As such, return and volatility shocks 
exhibit negative correlation throughout our sample, but this relation is heavily time-varying, showing remarkable swings in its magnitude. Negative dependence increases under stress, i.e. for market declines, but not for market upswings. Turning to an examination of the tails of the joint return-volatility distribution, we confirm this asymmetric behavior by a strict test of tail independence. Our results are shown to be robust with respect to a number of parameter choices. We document systemic market risk for large market declines and test for the role of both hypotheses in explaining extreme market movements. While we do not find return-volatility causality in either direction, our results suggest that both hypotheses play an important role in the contemporaneous explanation of extreme asymmetric volatility. We conclude that periods of market stress have substantial impact on asymmetric market volatility. The relation between market risk and return appears strong during periods of market stress. We particularly point out asset pricing implications under extreme volatility feedback, which helps to explain large market declines.

The remainder of the paper is organized as follows. Section 1 provides a review on asymmetric volatility. Our new model of conditional market returns and volatility is outlined in Section 2, which also includes our methodology for the study of the dependence between volatility and returns. In Section 3, we present the data set and the empirical results. The paper concludes in Section 4.

\section{Asymmetric Volatility}

In this section we give a brief review on asymmetric volatility. This review is intended to clarify some of the controversial points in the literature. While the term "asymmetric volatility" is sometimes not used consistently, the following definition appears consistent with most of the literature:

Asymmetric volatility states that returns and conditional volatility are negatively related and that this relation is more pronounced for negative returns.

The above definition covers three distinct characteristics, namely

- (i) a negative relation between (past) realized returns and conditional volatility, 
- (ii) a positive relation between conditional expected market returns and volatility and

- (iii) asymmetry, i.e. relation (i) is more pronounced for negative returns.

The first empirical finding, (i), is linked to the discussion of the "leverage effect" hypothesis. The hypothesis can be traced back to the work of Black (1976) and Christie (1982). It states that, once market prices of equity drop, financial leverage of the firm increases and, as a result, the volatility of equity price changes increases. Christie (1982) examines the relation for riskless debt as well as for risky debt within the framework of a structural credit risk model. For increasing leverage, he predicts a monotonically (non-monotonically) decreasing strength in the negative relation between stock returns and volatility for the riskless (risky) debt model. Hence, while the leverage hypothesis explains a negative relation (i), even with risky debt, the observation of asymmetry, (iii), would require additional assumptions. To our knowledge, there is no such attempt in the literature so far, and this may in part explain why most studies conclude that the leverage effect cannot fully explain the phenomenon of asymmetric volatility; see also Aydemir, Gallmeyer, and Hollifield (2006).

The second and third characteristic, (ii) and (iii), both follow within an intertemporal asset pricing context as given for example by Merton $(1973,1980)$. Assuming further that volatility is persistent (as documented in the literature, see e.g. Bollerslev, Chou, and Kroner (1992)), an increase in conditional stock market volatility predicts increased future volatility, which may increase required future market returns, and thus lower present prices. Note that this argumentation can also explain characteristics (i) and (ii) above. It is the cornerstone of the volatility feedback effect hypothesis, which was proposed (also) by Black (1976) as well as by Pindyck (1984), French, Schwert, and Stambaugh (1987) and Campbell and Hentschel (1992).

As Campbell and Hentschel (1992) argue, volatility feedback can explain observation (iii), i.e. it may explain why volatility is asymmetric. Given a large piece of unexpected good news, i.e. a large positive return shock, volatility increases and feedback yields a decrease in prices, which in turn dampens the initial positive return shock. However, given a large piece of unexpected bad news, i.e. a large negative return shock, volatility increases and feedback yields an additional decrease in prices, which in turn amplifies the initial negative return shock. As a result, volatility is asymmetric, because volatility feedback amplifies negative 
stock returns while it dampens positive returns. Consistent with findings in the empirical literature, volatility feedback can explain why market returns tend to be negatively skewed and why changes in market volatility typically show positive skewness. We argue that the feedback effect has to converge and eventually reach a steady state, as otherwise - given an initial large piece of bad news - the market could be predicted to melt down. Systemic market risk is, among others, described by the probability of such an extreme event.

Given both hypotheses above, it can be supposed that leverage and feedback jointly drive asymmetric volatility in equity markets. Bekaert and $\mathrm{Wu}(2000)$ provide a first empirical study on the explanation of asymmetric equity market volatility based on leverage as well as feedback effects. They conclude that leverage models cannot explain the observed patterns (on the firm as well as on the aggregate market level), while volatility feedback appears more plausible. Bae, Kim, and Nelson (2007) support these findings. Controlling for leverage, they show that in contrast to temporary volatility changes, only persistent volatility changes feed back to stock returns. Economic models of asymmetric volatility may explain equilibrium return/volatility dynamics driven by feedback (as e.g. in $\mathrm{Wu}(2001)$ ) or driven by leverage (as e.g. in Aydemir, Gallmeyer, and Hollifield (2006)).

Econometric models of asymmetric volatility improve the modeling and forecasting of conditional volatility by incorporating observation (iii) above. Frequently, these models also make predictions of the conditional risk-return relation (ii). The most widespread class of models is ARCH models (see e.g. Bollerslev, Chou, and Kroner (1992)). Asymmetric model versions include the Nelson (1991) EGARCH model and threshold ARCH models including for example the GJR-GARCH model of Glosten, Jagannathan, and Runkle (1993), the model of Zakoian (1994) and the model of Engle and Ng (1993). Regime switching models with asymmetry are used by Kim, Morley, and Nelson (2004) and by Bae, Kim, and Nelson (2007).

So far, only a few studies have used observable approximations to the unobservable market volatility process. Bollerslev, Litvinova, and Tauchen (2006) use realized intraday volatility in order to examine volatility asymmetry. They find evidence of both, a prolonged leverage as well as an almost instantaneous feedback effect at the intradaily level. ${ }^{1}$ As in the present study, Wu and Xiao

\footnotetext{
${ }^{1}$ Note that this finding of Bollerslev, Litvinova, and Tauchen (2006) confirms some of the predictions of Black (1976), p. 180: "We would never expect to find a delay from volatility
} 
(2002) and Hibbert, Daigler and Dupoyet (2008) use the VIX index as an observable approximation of conditional volatility. Given nonparametric results on asymmetric volatility, $\mathrm{Wu}$ and Xiao (2002) compare the fit of various asymmetric ARCH models. They show that a modified version of the EGARCH model provides a decent fit. They also note that the impact of large shocks may be of interest, however, they conclude that "we do not have enough sample points in the tail to be able to make a prediction at a very high confidence level." (Wu and Xiao (2002), p. 302). Based on quantile regression results, Hibbert, Daigler and Dupoyet (2008) find that both large positive as well as large negative asset returns are more strongly associated with changes in implied volatility. To date, none of the studies considered large scale volatility feedback, i.e. the question wether leverage or feedback may systematically relate to market stress.

Recent research indicates that asymmetric volatility is more closely linked to asset pricing issues than previously considered with the above two competing traditional hypotheses. Along these lines, Avramov, Chordia and Goyal (2006) document that order flow can explain asymmetric volatility, where, conditional on a negative return, volatility is higher after large volume days. Their empirical findings also support the authors' hypothesis that large contrarian trades decrease volatility while large herding trades increase volatility. Another trading-based explanation of asymmetric volatility is given by Wagner and Marsh (2005) who extend the GJR-GARCH model via asymmetric volume effects. Their findings show that asymmetric market volatility and a positive conditional risk-return relationwhich is weak under the original GJR-specification-both become significant under a volume specification, i.e. when the GJR-model accounts for volume shocks, which may proxy private information flow. A related finding is given in Smith (2007), who shows that incorporating volatility feedback in a stochastic volatility model transforms a weak negative risk-return relation into a statistically significant positive relation. These findings would suggest an extension of the Campbell and Hentschel (1992) argumentation. Apart from an initial return shock, a private information shock may initiate the volatility feedback effect. When such a shock is substantial, this typically yields an observable positive shock to trading volume ${ }^{2}$

changes to stock returns. [...] There might be some delayed effects in the other direction, though. I suspect that changes in volatility caused by stock price changes tend to decay over time."

${ }^{2}$ Of course, apart from a situation of asymmetric information, any form of investor disagreement may play an important role here. 
and a persistent increase in market volatility, which in turn starts the feedback effect. Hibbert, Daigler and Dupoyet (2008) find that the return-implied volatility relation is foremost a contemporaneous relation. They consider their findings as evidence of behavioral biases, which may explain asymmetric volatility.

As Beakert and $\mathrm{Wu}(2000)$ point out, if relation (ii) between conditional market volatility and expected return is not positive, the validity of a time-varying market risk premium hypothesis is in doubt. In fact, once changes in conditional expected market returns are related to persistent changes in today's conditional market volatility, volatility risk is a priced risk factor; see also Li (2004) and Engle and Mistry (2007). As (ii) implies (iii) above via the volatility feedback effect, Engle and Mistry suggest that testing for volatility asymmetry is equivalent to testing for priced risk factors.

Overall, the above findings suggest that leverage and volatility feedback as well as liquidity and private information flow may help to explain the characteristics of asymmetric volatility. Volatility feedback appears central and relies on a positive relation between conditional expected market returns and market volatility. As a consequence, asymmetric volatility is not only an important characteristic of the market volatility dynamics but a fundamental characteristic of priced risk factors.

\section{Methodology}

Our methodology captures the joint distribution of returns and conditional volatility as an asymmetric stochastic volatility process. We thereby treat returns and volatility as observable variables, while the volatility of volatility is unobservable. We model conditional market returns in the spirit of a parsimonious stochastic volatility model with constant mean return and with the VIX as an observable proxy of conditional market volatility. The VIX conditional market variance changes are modeled as a GJR-GARCH process. Hence, we propose a new model with a standard "leverage"-effect between lagged market returns and changes in conditional volatility and with a volatility of volatility changes, which is in turn asymmetric. What remains are unexpected shocks to market returns and conditional market volatility.

Our aim is to examine the nature of asymmetric market volatility in our above model setting. We do this by a detailed study of the negative dependence between the unexpected return and volatility shocks. In order to examine correlation, we consider DCC in the multivariate GARCH framework of Engle (2002) and Engle 
and Sheppard (2001). This allows us to characterize the time-varying nature of the negative relation between realized returns and conditional volatility. In order to examine the tail behavior of large unexpected shocks to returns and variance, we apply models of bivariate EVT. A general discussion of EVT with a background in finance is by Embrechts, Klüppelberg and Mikosch (1997). Summaries on univariate and bivariate results can be found in Coles (2001) and Beirlant, Goegebeur, Segers, and Teugels (2004), for example. EVT analysis allows us to study asymmetric volatility under market stress and to test the implications of the feedback hypothesis. ${ }^{3}$

\subsection{Market Returns, Volatility and Volatility of Volatility}

Our model of conditional market returns, volatility and volatility of volatility is based on a discrete time stochastic volatility approach for the dynamics of returns and volatility. In short, we model conditional returns, volatility and volatility of volatility in the spirit of a double-asymmetric process.

For the periods, $t=1, \ldots, T$, the conditional market returns $R_{t}$ are given as

$$
R_{t}=\mu+Y_{t} \sigma_{t}
$$

where $\mu \in \mathbb{R}$ and the return shocks are independent and identically distributed (iid) following some symmetric distribution function $F, Y_{t} \sim \operatorname{iid} F_{Y}(0,1)$. In equation (2.1), the conditional market volatility, $\sigma_{t}$, is approximated by a positivelyvalued stochastic process, which is assumed to be directly observable via VIX volatility. ${ }^{4}$

Turning next to the model for VIX conditional market volatility, we model logarithmic changes in volatility as an autoregressive process of order $p \geq 1, \operatorname{AR}(p)$. We use lagged return innovations of equation (2.1) as explanatory variables, where

\footnotetext{
${ }^{3}$ Previous applications of bivariate extreme value theory in finance include Longin and Solnik (2001), Marsh and Wagner (2000), Poon, Rockinger, and Tawn (2004), Silvapulle and Granger (2001) and Straetmans, Verschoor and Wolff (2008).

${ }^{4}$ In order to allow for time series dependence in returns and for time-variation in expected returns based on past conditional volaility, we can e.g. set the conditional return expectation as: $\mu=\mu_{1}+\mu_{2} R_{t-1}+\mu_{3} \sigma_{t-1}$. However, in unreported empirical investigations, the coefficients for lagged returns and lagged volatility turn out to be insignificant based on White heteroskedasticity consistent estimates of the standard errors. We conclude that the simple constant mean model proves to be sufficient for our purposes.
} 
a threshold specification allows conditional volatility to react asymmetrically to past return shocks. In detail, we assume

$$
\Delta \ln \sigma_{t}=\sum_{j=1}^{p} \delta_{j} \Delta \ln \sigma_{t-j}+f\left(Y_{t-1} ; \sigma_{t-1}\right)+Z_{t} \phi_{t}
$$

where the $Z_{t}$ represent white noise innovations, $Z_{t} \sim \operatorname{iid} F_{Z}(0,1)$. We can rearrange the above equation and obtain a model for the conditional logarithmic volatility. We have:

$$
\ln \sigma_{t}=\left(1+\delta_{1}\right) \ln \sigma_{t-1}-\delta_{1} \ln \sigma_{t-2}+\sum_{j=2}^{p} \delta_{j} \Delta \ln \sigma_{t-j}+f\left(Y_{t-1} ; \sigma_{t-1}\right)+Z_{t} \phi_{t} .
$$

For $\delta_{1}=0$, it follows that the above equation has a unit root. With $\delta_{j}=0, j=$ $1, \ldots, p$, the process is a non-stationary random walk, i.e. an integrated volatility process. Otherwise, for $-2<\delta_{1}<0$, a stationary solution may result. For the remaining parameters we assume $-1<\delta_{j}<1, j=2, \ldots, p$.

We may specify various parametric functions $f$ in equation (2.2). As motivated by threshold ARCH models, we choose the following three alternative piecewise linear specifications

$$
\begin{aligned}
& f_{1}\left(Y_{t-1} ; \sigma_{t-1}\right)=\omega_{0}+\omega_{1}\left|Y_{t-1} \sigma_{t-1}\right|+\omega_{2}\left|Y_{t-1} \sigma_{t-1}\right| I_{\left\{Y_{t-1} \sigma_{t-1}<0\right\}} \\
& f_{2}\left(Y_{t-1} ; \sigma_{t-1}\right)=\omega_{0}+\omega_{1}\left|Y_{t-1}\right|+\omega_{2}\left|Y_{t-1}\right| I_{\left\{Y_{t-1}<0\right\}} \\
& f_{3}\left(Y_{t-1} ; \sigma_{t-1}\right)=\omega_{0}+\omega_{1}\left|Y_{t-1} \sigma_{t-1}\right|+\omega_{2}\left|Y_{t-1} \sigma_{t-1}\right| I_{\left\{Y_{t-1} \sigma_{t-1}<\theta\right\}}
\end{aligned}
$$

where $I_{\{A\}}$ denotes the indicator variable for the event $A$ and $\theta, \omega_{0}, \omega_{1}, \omega_{2} \in \mathbb{R}$. The above specifications allow conditional volatility to react asymmetrically to return shocks. In particular, the models may explain skewness in the distribution of volatility changes. The typical specification, $f_{1}$, distinguishes between positive and negative lagged returns. Specification $f_{2}$ follows $f_{1}$ but depends only on lagged return shocks not volatilities. Specification $f_{3}$ allows for a threshold $\theta \neq 0$ in specification $f_{1}$, i.e. we may examine asymmetry for two arbitrary return intervals $(-\infty ; \theta)$ and $[\theta ; \infty)$.

On the subsequent level, we allow for heteroskedasticity in logarithmic volatility changes, which are given in equation (2.2). The conditional variance of the logarithmic conditional market volatility, $\phi_{t}^{2}$, is assumed to follow an asymmetric GJR-GARCH equation of the form

$$
\phi_{t}^{2}=\gamma_{0}+\gamma_{1}\left(Z_{t-1} \phi_{t-1}\right)^{2}+\gamma_{2}\left(Z_{t-1} \phi_{t-1}\right)^{2} I_{\left\{Z_{t-1} \phi_{t-1}<0\right\}}+\gamma_{3} \phi_{t-1}^{2} .
$$


Note that a positive variance $\phi_{t}^{2}$ is normally assured under the sufficient parameter restrictions $\gamma_{0}>0, \gamma_{1}, \gamma_{2}, \gamma_{3} \geq 0$.

The iid innovations $\left(Y_{t}, Z_{t}\right)$ drive the above bivariate return-volatility model, which is defined by equations (2.1), (2.2) and (2.3). The innovations may exhibit cross-sectional dependence as characterized by their joint distribution function $F$. We address the joint distribution of $\left(Y_{t}, Z_{t}\right)$ in the following.

\subsection{Time-Varying Asymmetric Volatility}

Given our above model of the market dynamics, we now turn to a model of the joint distribution of unexpected market returns and variance changes. Assuming a time-varying contemporaneous correlation between returns and variance, we can write

$$
\left(R_{t}, \sigma_{t}^{2}\right)^{T} \mid R_{t-1}, \sigma_{t-1}^{2}, Z_{t-1}, \phi_{t-1}^{2}, \rho_{t-1} \sim G_{\Sigma_{t}} \quad \text { with: } \Sigma_{t}=\left(\begin{array}{cc}
\sigma_{t}^{2} & \rho_{t} \sigma_{t} \phi_{t} \\
\rho_{t} \sigma_{t} \phi_{t} & \phi_{t}^{2}
\end{array}\right) .
$$

In (2.4), $\Sigma_{t}$ denotes the time-varying positive definite variance-covariance matrix of the pair $\left(R_{t}, \sigma_{t}^{2}\right)$. Given equations (2.1), (2.2) and (2.3) above, unexpected returns and unexpected volatility changes, $\left(Y_{t}, Z_{t}\right)$, follow a joint distribution $F$ with given positive definite variance-covariance matrix $\Omega_{t}$

$$
\left(Y_{t}, Z_{t}\right)^{T} \mid Y_{t-1}, Z_{t-1}, \rho_{t-1} \sim F_{\Omega_{t}} \quad \text { with: } \Omega_{t}=\left(\begin{array}{cc}
1 & \rho_{t} \\
\rho_{t} & 1
\end{array}\right)
$$

The unexpected returns and unexpected volatility changes have standardized marginal distributions and their contemporaneous correlation (or covariance in this setting) is given by $\rho_{t}$. The time-varying correlations describe volatility asymmetry under normal market conditions. We now assume DCC-dynamics for the conditional correlations, i.e.

$$
\rho_{t}=\frac{q_{t}}{\sqrt{q_{Y, t} q_{Z, t}}} .
$$

In equation (2.6), the conditional covariance, $q_{t}$, and the conditional variances, $q_{Y, t}$ and $q_{Z, t}$, each follow GARCH(1,1)-type processes

$$
\begin{aligned}
q_{t} & =\bar{\rho}+v_{1}\left(Y_{t-1} Z_{t-1}-\bar{\rho}\right)+v_{2}\left(q_{t-1}-\bar{\rho}\right), \\
q_{Y, t} & =1+v_{1}\left(Y_{t-1}^{2}-1\right)+v_{2}\left(q_{Y, t-1}-1\right), \\
q_{Z, t} & =1+v_{1}\left(Z_{t-1}^{2}-1\right)+v_{2}\left(q_{Z, t-1}-1\right),
\end{aligned}
$$


with $v_{1}+v_{2}<1$. The unconditional covariance is given by $\bar{\rho}=\sigma_{Y Z} \sigma_{Y}^{-1} \sigma_{Z}^{-1}$, which equals $\mathbb{E}\left(Y_{t} Z_{t}\right)$ for standardized variables.

\subsection{Extreme Asymmetric Volatility}

In order to characterize asymmetric volatility under periods of stress, we consider an EVT approach. We proceed in two steps, considering the marginal distributions first and then the dependence via an EVT-copula approach.

In the first step, in order to model the extreme behavior of the iid univariate changes, $Y_{t}=Y$ and $Z_{t}=Z$, we assume that the marginal distributions of $F$, denoted e.g. by $F_{X}$, can by characterized by results from EVT, which makes only weak assumptions about the distribution and requires that the univariate changes are iid (see e.g. Embrechts, Klüppelberg and Mikosch (1997)). Without loss of generality, we have

$$
1-F_{X}(x)=P(X>x)=P(-X<-x)=F_{-X}(-x),
$$

and we restrict our discussion to upper tails in the following. We study return maxima $Y$, return minima $-Y$, volatility maxima $Z$ and volatility minima $-Z$, i.e.: $X \in\{Y,-Y, Z,-Z\}$.

We use a convenient Pareto tail approximation for excesses of a sufficiently high threshold, $u>0$. EVT shows that a suitable asymptotic approximation is the Generalized Pareto Distribution (GPD), which is parameterized by a tail index $\xi \in \mathbb{R}$ and a scaling parameter $\beta>0$. Conditional on $X>u$, a random number of excesses, $X-u>0$, follows a GPD tail approximation. Considering the case $\xi \geq 0$, the GPD is given by:

$$
1-H_{X}(x)=\left\{\begin{array}{c}
\left(1+\xi \frac{x-u}{\beta}\right)^{-1 / \xi}, \xi>0 \\
\exp \left(-\frac{x-u}{\beta}\right), \xi=0
\end{array} .\right.
$$

In the second step, we model the joint extreme behavior of the unexpected changes $(Y, Z)$, conditional on $Y>u_{Y}$ and $Z>u_{Z}$. We assume that the extreme behavior of the joint distribution function $F$ can be characterized via the Pickands (1981) EVT-copula approach. Given our first step, both variables $Y$ and $Z$ are transformed to identical marginal distributions, which may be given e.g. by the standard Fréchet distribution. Then, the Pickands representation theorem shows 
that a potential bivariate limiting distribution $H$, satisfying the required maxstability condition, has to be of the form

$$
H(y, z)=\exp \left\{-\left(\frac{1}{y}+\frac{1}{z}\right) A\left(\frac{y}{y+z}\right)\right\} .
$$

The limiting distribution $H$ has a unique EVT-copula, which is defined via the dependence function $A(w):[0,1] \mapsto[0,1] . A(w)$ characterizes bivariate extreme dependence. If $A(w)=1$, the tails of the joint distribution are independent, whereas $A(w)=\max (w, 1-w)$ indicates perfect dependence. We choose two common parametric models for $A(w)$. A first model is the symmetric logistic model, which relates to the Gumbel (1960) copula, where

$$
A_{\alpha}(w)=\left\{(1-w)^{1 / \alpha}+w^{1 / \alpha}\right\}^{\alpha}
$$

with $0<\alpha \leq 1$. Independence is reached when $\alpha=1$ and perfect dependence when $\alpha \rightarrow 0$. A generalization of the Gumbel copula allows for asymmetric dependence with

$$
A_{\alpha, \theta_{1}, \theta_{2}}(w)=\left(1-\theta_{1}\right)(1-w)+\left(1-\theta_{2}\right) w+\left\{(1-w)^{1 / \alpha} \theta_{1}^{1 / \alpha}+w^{1 / \alpha} \theta_{2}^{1 / \alpha}\right\}^{\alpha},
$$

where $0<\alpha \leq 1$ and $\theta_{1} \geq 0, \theta_{2} \leq 1$; see Tawn (1988). Under the asymmetric model, symmetry is obtained under $\theta_{1}=\theta_{2}=1$ and independence is reached when either $\alpha=1, \theta_{1}=0$ or $\theta_{2}=0$.

While the unexpected changes $(Y, Z)$ may exhibit significant dependence, dependence could vanish gradually, leaving them asymptotically independent in the joint tail. Such behavior would not be suitable to the above threshold model, which is based on the assumption that extreme value dependence holds above the thresholds $u_{Y}$ and $u_{Z}$; see Ledford and Tawn (1996). Formally, consider the limiting conditional probability

$$
\chi=\lim _{u \rightarrow \infty} P(Y>u \mid Z>u),
$$

where the case $\chi=0$ denotes asymptotic independence and $\chi>0$ denotes asymptotic dependence. It can be shown that $\chi=2-2 A(1 / 2)$ for any limiting distribution $H$ in equation (2.8); see e.g. Coles (2001, p.164). Hence, it follows that $\chi=2-2^{\alpha}$ for model (2.9) and that $\chi=\theta_{1}+\theta_{2}-2\left\{\left(\theta_{1}\right)^{1 / \alpha}+\left(\theta_{2} / 2\right)^{1 / \alpha}\right\}^{\alpha}$ for model (2.10). 
In order to examine the above two cases of extreme dependence, we use two approaches from the literature. First, Coles, Heffernan and Tawn (1999) define the following pair

$$
\begin{aligned}
& \chi(u)=2-\frac{\ln P\left(F_{Y}(Y)<u, F_{Z}(Z)<u\right)}{\ln P\left(F_{Y}(Y)<u\right)}, \lim _{u \rightarrow 1} \chi(u)=\chi, \quad \chi \in[0,1], \\
& \bar{\chi}(u)=\frac{2 \ln P\left(F_{Y}(Y)>u\right)}{\ln P\left(F_{Y}(Y)>u, F_{Y}(Y)>u\right)}-1, \lim _{u \rightarrow 1} \bar{\chi}(u)=\bar{\chi}, \quad \bar{\chi} \in[-1,1] .
\end{aligned}
$$

They show that, in the case of asymptotic independence, i.e. when $\chi=0$, it follows, $\chi(u) \rightarrow 0$ and $\bar{\chi}(u) \rightarrow$ const. $<1$. Under asymptotic dependence, i.e. when $\chi>0$, it follows, $\chi(u) \rightarrow$ const. $>0$ and $\bar{\chi}(u) \rightarrow 1$. Second, Falk and Michel (2006) consider the asymptotic conditional distribution of the sum $Y+Z$, which yields the following testable implication:

$$
\lim _{u \rightarrow \infty} P(Y+Z \leq t \mid Y+Z>u)=\left\{\begin{array}{l}
t^{2}: \text { iff } \chi=0 \\
t: \text { otherwise }
\end{array} .\right.
$$

\subsection{Hypotheses}

In this section we address asymmetric volatility by formulating testable hypotheses for unexpected return and volatility shocks. We first consider hypotheses, which are implied by both, feedback and leverage. Then we consider extreme volatility feedback as opposed to leverage. In total, we put up seven hypotheses, which we subsequently consider in our empirical investigation.

\subsubsection{Feedback and Leverage}

Following Section 1, a first testable hypothesis, which is implied by both feedback and leverage, is that of a contemporaneous negative relation (i) of Section 1. This implies a negative correlation $\bar{\rho}$ between unexpected return and volatility shocks, $\left(Y_{t}, Z_{t}\right)$, i.e. we would at least attempt to reject $\mathrm{H}_{0}^{(1)}: \quad \bar{\rho} \geq 0$. By examining the tails of the joint distribution, we test the hypothesis of dependence between the extremes of $\left(Y_{t}, Z_{t}\right)$. We formulate the 'boom' scenario, $\mathrm{H}_{0}^{(2)}$ : " $\left(Y_{t},-Z_{t}\right)$ are asymptotically independent" and the 'crash' scenario, $\mathrm{H}_{0}^{(3)}: \quad$ " $\left(-Y_{t}, Z_{t}\right)$ are asymptotically independent". In the case of extreme asymmetric market volatility, we expect to reject $\mathrm{H}_{0}^{(3)}$ but fail to reject $\mathrm{H}_{0}^{(2)}$. 


\subsubsection{Feedback versus Leverage}

Testing the leverage effect hypothesis against the feedback effect hypothesis is clearly non-trivial as both hypotheses predict a contemporaneous negative volatilityreturn relationship. Given our discussion in Section 1, we argue that asymmetry, i.e. point (iii) in Section 1, is particularly supported by the feedback hypothesis of Campbell and Hentschel (1992), but not by the leverage models of Christie (1982). That is, under extreme volatility feedback we would particularly predict

that the dependence between $Y$ and $-Z$ in $\mathrm{H}_{0}^{(2)}$ is weaker than that between $-Y$ and $Z$ in $\mathrm{H}_{0}^{(3)}$.

Furthermore, as discussed in Section 1, there is agreement in the literature that the leverage and the feedback effect hypotheses differ in their causality. ${ }^{5}$ In order to test for potential causality, we consider whether lagged unexpected price shocks relate to unexpected conditional volatility shocks of opposite sign and vice versa. This forms the following two hypotheses: $\mathrm{H}_{0}^{(4)}$ : " $\left(-Y_{t-1}, Z_{t}\right)$ are asymptotically independent" as a null hypothesis in order to test for leverage and $\mathrm{H}_{0}^{(5)}$ : " $\left(-Y_{t}, Z_{t-1}\right)$ are asymptotically independent" as a null hypothesis in order to test for feedback. Additionally, we may test for asymmetry within the contemporaneous dependence relation as put up by hypothesis $\mathrm{H}_{0}^{(3)}$. On an operational level, we thereby test for the exchangeability of both variables, i.e. we test $\mathrm{H}_{0}^{(6)}$ : " $\left(-Y_{t}, Z_{t}\right)$ have a symmetric dependence relation".

Finally, we may interpret the asymptotic probability $\chi$ as given in equation (2.11) as the probability of extreme volatility feedback. The variable denotes the conditional probability of a large shock to market returns, given a large shock to volatility, i.e. it describes the market melt-down probability due to extreme volatility feedback. We test the (leverage effect) null hypothesis of no extreme feedback, i.e.: $\mathrm{H}_{0}^{(7)}: \quad \lim _{u \rightarrow \infty} P\left(-Y_{t}>u \mid Z_{t}>u\right)=0$.

\footnotetext{
${ }^{5}$ See e.g. Black (1976), Beakert and Wu (2000) and Bollerslev, Litvinova, and Tauchen (2006). Note that causality is a difficult concept in economics where the fact that some event A regularly occurs before another event B does not imply that "A causes B" in a strict sense. See e.g. the discussion in Black (1976).
} 


\section{Empirical Investigation}

This section first introduces the data set used in our empirical study. It then outlines how the model of Section 2 is implemented. Finally, we describe our estimation results, consider the hypotheses of Section 2.4 and then give an interpretation of our findings. ${ }^{6}$

\subsection{The Dataset}

Our dataset consists of two time series for the U.S. equity market, namely daily closing price data and VIX implied volatility data for the Standard and Poor's 500 index (S\&P 500). The sample spans 4891 daily observations during the period from January 2, 1990 to September 30, 2008. We point out that our sample period contains several episodes of financial market stress. Prominent examples are the 1990 to 1991 Gulf War period, the October 1997 East Asian currency crisis, the August to September 1998 Russian debt crisis and the related near-collapse of Long Term Capital Management. Further market stress episodes are the burst of the internet bubble starting in April 2000, the September 11, 2001 terror attacks, a period of several corporate sector bankruptcies in late 2001 to 2002 (including e.g. Enron, Tyco and WorldCom) and finally the 2007 to 2008 financial crisis with many large financial institutions under severe distress (including e.g. American International Group, Bear Stearns, Fannie Mae, Freddie Mac, Lehman Bros. and Washington Mutual).

Our S\&P 500 price data are closing index quotes as obtained from Thomson Financial Datastream. Continuously compounded index returns are derived as $R_{t}=\ln I_{t}-\ln I_{t-1}, \quad t=1, \ldots, 4890$. The implied volatility data are given by the VIX, which is calculated by the Chicago Board Options Exchange, CBOE. The VIX has rapidly become the benchmark for stock market volatility since its introduction in 1993 and may be seen as an "investor fear gauge" following Whaley (2000). The original VIX was built as a proxy of at-the-money implied volatility with a one-month time to maturity. As the volatility index was, among other issues, criticized due to its upward bias, $\mathrm{CBOE}$ decided to amend the index construction in 2003. Two changes were then brought to the calculation. First, the new VIX is now no longer computed from at-the-money strikes only, but also

\footnotetext{
${ }^{6}$ We gratefully acknowledge the use of $\mathrm{R}$ for parts of our calculations: $\mathrm{R}$ Development Core Team 2003, A language and environment for statistical computing, R Foundation for Statistical Computing, Vienna.
} 
includes a set of out-of-the money calls and puts. Its computation is directly based on index option prices rather than on single implied volatilities. Second, the new VIX computation uses options written on the broader S\&P 500 index rather than the S\&P 100 index. For more details on the VIX calculation the reader may refer to CBOE (2003).

Given these changes in index construction, the new VIX can be regarded as an approximation of the variance swap rate. Formally, the VIX represents the risk-neutral expectation of future quadratic variation in S\&P 500 index returns, see Todorov and Tauchen (2008), for example. As a consequence, we expect differences in the behavior of conditional volatility under the physical and under the risk-neutral probability measure. However, several studies use the series as an observable market volatility series, which is highly sensitive with respect to the underlying latent volatility process, see e.g. Wu and Xiao (2002) and Todorov and Tauchen (2008). Also, the VIX is a forward looking measure and therefore wellsuited to proxy conditional volatility. Based on the above considerations, we use the new VIX as a proxy of conditional implied market volatility. Strictly speaking, we study asymmetric volatility under the risk-neutral measure. In detail, we use $\sigma_{t}=1 / \sqrt{250} \cdot(\mathrm{VIX} / 100)$ as an observable approximation of daily conditional market volatility.

\subsection{Estimation Results and Implications}

\subsubsection{Unexpected Returns and Volatility Changes}

A summary of the results of estimating model (2.1-3) for our data set is given in Table 1. We find that estimated residuals which are approximately iid, i.e. the unexpected return and volatility shocks, $\left(Y_{t}, Z_{t}\right)$, which we derive from the model are short range independent and follow a homoskedastic distribution. We refer to Table 1, which reports the results for the index returns (Ljung-Box $Q(k)$ statistics for $Y_{t}$ and $Y_{t}^{2}$ ) and the results for the VIX changes (Ljung-Box $Q(k)$ statistics for $Z_{t}$ and $Z_{t}^{2}$ ) as well as results of Engle's ARCH-LM test for $Z_{t}$, with lags $k=1,2,3$. For the unexpected return shocks short range evidence is similar to that for volatility with some dependence at lag 3 . The unexpected volatility changes can well be assumed to be uncorrelated as well as homoskedastic as we cannot reject the null hypotheses of neither the Ljung/Box nor the Engle ARCHLM statistics at the 95 percent confidence level.

For model (2.1), the sample average return is $\widehat{\mu}=0.000241$ and we calculate 
standardized unexpected returns as $\left(R_{t}-\widehat{\mu}\right) / \sigma_{t}=Y_{t}$. The return shocks $Y_{t}$ have a sample average of 0.0265 and the sample standard deviation is 0.74 . They are short-range approximately homoskedastic as can be seen from the Ljung/Boxstatistics in Table 1. We note that return shock distribution is well approximated by a standardized Student-t distribution, where the estimated value for the degrees of freedom equals 8.97. This finding indicates moderate tail fatness in S\&P market returns once they are standardized by the VIX series.

We next perform an estimation of our novel model for logarithmic volatility, $\ln \sigma_{t}$, according to equations (2.2) and (2.3) with lagged residuals, $R_{t-1}-\widehat{\mu}$, as explanatory variables. Our estimates follow from the maximum likelihood (ML) approach under the assumption of a Student-t distribution with $\nu$ degrees of freedom for the noise terms. We choose $p=4$ in order to account for linear time-series dependence in logarithmic volatility, a choice which appears suitable but does not heavily impact our estimation results. As to be expected, log VIX volatility is persistent. This is documented by the $\delta_{j}$-estimates for example for the asymmetric specification based on function $f_{1}$. The estimate of $\delta_{1}$ is significantly smaller than zero (value of -0.059 with a t-statistic of -3.14 ). The estimates of the remainder parameters, $\delta_{2}, \delta_{3}$ and $\delta_{4}$, are significantly negative as well (values of $0.082,-0.060$, and -0.063 with t-statistics of $-5.84,-4.35$ and -4.57 , respectively). Hence, we can reject the hypothesis of a (non-stationary) random walk in (2.2) at the 99 percent confidence level. Table 1 reports parameter estimation results for the asymmetric specification based on $f_{1}$. The estimated value for $\nu$ is 5.27 with a standard error of 0.36 , which indicates fat tails in the distribution of the $Z_{t}$ 's. The above specification $f_{1}$ is chosen for the standardized residuals $Z_{t}$ in our subsequent analysis. As a robustness check, we also derive estimation results for the alternative specifications $f_{2}$ and $f_{3}$ and find that the results are very similar to those obtained from specification $f_{1}$. This lets us conclude that the results robust with respect to the choice of the asymmetry threshold $\theta$, where we chose parameters in the range between -0.025 and 0.025 . Detailed results are available from the authors upon request.

The results for our GJR-GARCH specification (2.2) and (2.3) based on specification $f_{1}$ are reported in Table 1 . They reveal several interesting features of logarithmic VIX volatility. First, as stated above, the given time-series specification allows us to remove linear and quadratic time-series dependence in log volatility changes. This is our main objective in the present study. Second, for lagged returns, our model indicates a statistically insignificant leverage effect but 
a significant hyper-level leverage effect. Interestingly, the asymmetric volatility effect, as measured by $\omega_{2}$, exhibits insignificant negative sign. Given that the logarithm is a strictly increasing transformation, negative parameter estimates of $\omega_{1}$ and $\omega_{2}$ suggest that lagged return shocks yield somewhat lower subsequent volatility levels. Hence, negative lagged return shocks predict an insignificant decrease in conditional volatility. It therefore appears that the contemporaneous asymmetric negative dependence quickly reverts to a lagged weakly positive dependence, i.e. market volatility tends to somewhat decline one day after a negative market return shock. In sum, we do not find a significant leverage effect for lagged returns. However, on the hyper-level, we find such asymmetry as the coefficient $\gamma_{2}$ estimate is significantly negative. While the significant asymmetry in the estimated volatility of volatility relation violates the typical GJR positivity constraints, this does not pose an economic problem for our model of logarithmic volatility, where (2.2) assures strict positivity. Also, we find that conditional volatility of volatility is estimated to have positive values throughout our sample. From the given estimation results, we can conclude that volatility of volatility positively relates to lagged volatility as shown by a significantly positive parameter $\gamma_{1}$. However, volatility of volatility is strongly asymmetric in the sense that once lagged market volatility drops, such positive comovement significantly vanishes as shown by the aggregate effect of $\gamma_{1}$ and $\gamma_{2}$. In summary, this finding lets us conclude that positive volatility shocks drive positive shocks in volatility of volatility. We graphically illustrate our results in Figure 1. The figure shows a plot of our estimation of volatility of volatility as well as plots of market returns and conditional VIX volatility. As can be seen from Figure 1, large absolute market returns may relate to jumps in both series, while the jump magnitude may be high in volatility but not in volatility of volatility and vice versa.

\subsubsection{Time-Varying Asymmetric Volatility}

Based on our discussion in Section 2, we now test for of the time-varying behavior of asymmetric volatility. There is reason to believe that the negative relation between market volatility and returns is not constant but stronger in some states of the economy than in others. Both our hypotheses, leverage and feedback, do not make clear predictions on such effects. Therefore, our empirical investigation sheds new light on this issue and estimate the DCC model according to equation (2.5). The log-likelihood function is given in Engle (2002) and Engle and Sheppard 
(2001), who note that conditional multivariate normality is an ML-estimation assumption, which is not required for the consistency and the asymptotic normality of the DCC estimator.

Table 2 documents that the unconditional correlation coefficient is significantly different form zero. In fact, we can reject $\mathrm{H}_{0}^{(1)}$ at a the 95 percent confidence level. The value of the DCC maximized log-likelihood function, point estimates of the model parameters together with their standard errors are also given in Table 2. Both model parameters are significantly different from zero and their sum is smaller then one. The asymptotic test statistics show that we can reject the hypothesis of constant correlation as well as the hypothesis of uncorrelatedness of the shocks $Y_{t}$ and $Z_{t}$ both at high confidence levels. A graphical representation of the estimated correlation dynamics (2.6) together with conditional VIX volatility is given in Figure 2. It can be seen that estimated correlation stays below zero throughout the sample period. Higher levels of the VIX tend to coincide with lower levels of negative correlation between return and volatility shocks, and vice versa. In other words, a higher market risk relates to higher absolute correlation, i.e. volatility asymmetry appears more pronounced when conditional volatility is high. Given this evidence of a strong negative average correlation throughout our sample, we conclude that asymmetric market volatility appears to be a persistent phenomenon with time-varying magnitude.

\subsubsection{Asymmetric Volatility under Stress}

We now study the return and volatility shocks, $Y_{t}$ and $Z_{t}$, which are obtained from our GJR-GARCH specification (2.2-3) under periods of market stress. We thereby follow the idea of using an approximately iid series for EVT-analysis as for example proposed in Embrechts, Klüppelberg and Mikosch (1997) and Diebold, Schuermann and Stroughair (1998).

In order to study the extreme behavior of each marginal series, we first consider the GPD model (2.7). We perform a detailed pre-analysis in order to insure an appropriate threshold selection. In detail, we outline the results of four different methods of threshold selection in Table 3, namely use of the mean excess function (MEF) plot, use of the threshold plot, visual inspection based on these two plots as well as using an adaptive (i.e. automated) selection method. We choose an adaptive approach which aims at minimizing asymptotic mean squared estimation error as described in Section 4.7 ii of Beirlant, Goegebeur, Segers and Teugels 
(2004). We use the method in order to arrive at a threshold choice which is not guided by graphical (subjective) judgement. ${ }^{7}$ We find here that the threshold plot methods comes up with a range of possible threshold values, which is consistent with the results of the other three methods used. Figure 3 serves as an illustration of the MEF plot method, where we plot the sample MEF as an estimate of the mean excess function. Threshold selection is done by choosing the smallest threshold above which the MEF remains approximately a linear function of the threshold value. In order to prove robustness of our results, we performed GPD estimation based on both, the visual as well as the adaptive threshold selection of Table 3. For the 'crash' scenario, this implies an adaptive choice, $\left(u_{-y}, u_{z}\right)=(1.4,1.6)$, and a visual choice, $(1.2,1.5)$, where the choices are obviously close to each other. For the 'boom' scenario, the adaptive choice is $\left(u_{y}, u_{-z}\right)=(0.7,0.7)$ and the visual choice is $(1.5,1.5)$. Here, the choices diverge, but our basic tail dependence results are robust with respect to this choice. For reasons of space (alternative results are available from the authors upon request) we only present estimation results based on the more 'objective' threshold choice - i.e. the adaptive selection method - in the following.

In the next step, we follow Coles, Heffernan and Tawn (1999) as outlined in Section 2.3. The corresponding Chi- and Chi-Bar-plots are given in Figure 4. As can be seen from the resulting asymptotic behavior in these plots, 'boom' shocks $\left(Y_{t},-Z_{t}\right)$ appear asymptotically independent as $\chi(u) \rightarrow 0$ and $\bar{\chi}(u) \rightarrow 0.4>0$. However, 'crash' shocks $\left(-Y_{t}, Z_{t}\right)$ appear asymptotically dependent as $\chi(u) \rightarrow$ $0.6>0$ and $\bar{\chi}(u) \rightarrow 1$. Hence, we may apply the bivariate threshold model and interpret the convergence of $\chi(u)$ as a first estimate of $\chi$. We then perform a strict test of asymptotic independence. Falk and Michel (2006) propose four different test statistics to test for tail independence according to equation (2.14). We use their Kolmogorov-Smirnov (KS) test, as simulation results by the authors show that particularly the KS-test is well suited for our purposes. We choose a threshold value of -0.01 (i.e. $u=0.01$ ). For the crash scenario, the KS-statistic yields a value of 0.334 with a p-value of 0.085 . For the boom scenario, the KSstatistic results in a value of 0.396 with a p-value of 0.319 . Consequently, at the 90 percent confidence level, we can in fact reject the hypothesis that volatility and return shocks are tail independent in the crash scenario, while we can not reject

\footnotetext{
${ }^{7}$ Here, the small sample performance of adaptive approaches in financial applications is of interest. Commonly used automated threshold selection methods have to be treated with some caution not only under ARCH-effects but even if the underlying data are strictly independent.
} 
the independence hypothesis for the boom scenario.

From the above findings, we can draw three important conclusions. First, we have to reject $\mathrm{H}_{0}^{(3)}$ but fail to reject $\mathrm{H}_{0}^{(2)}$, which provides strict evidence of the phenomenon of extreme asymmetric volatility. Second, our rejection of $\mathrm{H}_{0}^{(3)} \mathrm{im}-$ plies a rejection of hypothesis $\mathrm{H}_{0}^{(7)}$ since both hypotheses state that $\chi=0$. Hence, empirical evidence suggests a non-zero asymptotic melt-down probability. Finally, for the crash scenario, $\left(-Y_{t}, Z_{t}\right)$, the bivariate threshold approach of Section 2.3 serves as a valid model. Therefore, we estimate the GPD model (2.7-8) jointly via MLE following the censored maximum likelihood approach of Ledford and Tawn (1996). Figure 5 serves as an illustration of the bivariate threshold approach, which models observations in the upper right corner of the plane of daily realized return and volatility shocks. Given our adaptive threshold choice, the ML estimation results for the marginal GPD distributions are given in Table 4. The estimation results for the symmetric and the asymmetric dependence model, (2.9) and (2.10), are given in Table 5 .

The results for the marginal GPD model in Table 4 indicate that positive return and negative volatility shocks are thin-tailed, while even negative return shocks show moderate tail behavior (i.e. the extreme value distributional limit is in the maximum domain of attraction of the Gumbel distribution). Hence, our initial ARCH model approach lacks fat-tailedness in positive volatility shocks, which exhibit a significantly positive tail index of 0.218 (with a standard error of 0.0670). The results in Table 5 demonstrate that the boom and the crash scenario both exhibit weak evidence of asymmetry within the dependence relation. This conclusion is supported by the estimated values of the asymmetry parameters of model (2.10) as well as by the given values of the Akaike information criterion (AIC). We therefore do not reject the symmetry assumption in $\mathrm{H}_{0}^{(6)}$ and consider only the symmetric model (2.9) in the following. The estimation results in Table 5 indicate extreme dependence for both booms as well as crashes (estimated alphas all significantly different from 1), while dependence appears slightly stronger for crashes. As outlined in Section 2.4, this finding supports extreme volatility feedback as opposed to leverage. This conclusion can still be maintained once we point out that the bivariate threshold approach serves as a strictly valid model only for the crash scenario (we reject $\mathrm{H}_{0}^{(3)}$ based on the KS-test), while it supposedly yields an overestimation of extreme dependence for the boom scenario. See also Ledford and Tawn (1996) for a discussion.

In an additional step we may test for causality in the joint tail using lagged 
variables. Rejection of the hypothesis $\mathrm{H}_{0}^{(4)}$ would indicate evidence for leverage, while a rejection of the hypothesis $\mathrm{H}_{0}^{(5)}$ would indicate evidence for feedback. However, as is turns out, lagged exceedances are rare in our sample and it is not possible to derive reliable statements or even to perform strict tests. Simply by counting events, we observe a feedback event, $\left(-Y_{t}>u_{-y}, Z_{t-1}>u_{z}\right)$, five times. In contrast, a leverage event, $\left(-Y_{t-1}>u_{-y}, Z_{t}>u_{z}\right)$, is observed eight times in our sample. While this could provide some evidence in favor of leverage. Considering unreported model parameter estimates as well as Chi and Chi-bar plots, we also have to emphasize that there is no evidence of asymptotic dependence in any form. Hence, we point out that extreme asymmetric volatility is characterized by a contemporaneous (i.e. intradaily) dependence relation.

In Table 6 we present estimated high-quantile exceedance probabilities for the symmetric logistic GPD model (2.9). The conditioning exceedance values are chosen as the $98,98.5,99,99.5,99.9$ and the 99.95 percent quantile of the respective marginal distributions. Reported are joint as well as conditional exceedance probabilities. Given that extreme asymmetric volatility is mostly an intradaily contemporaneous phenomenon, the conditional exceedance probabilities allow us to distinguish between intradaily leverage and feedback causality. As the results in Table 6 show, the conditional probability of a large return shock given a large volatility shock is slightly bigger than the reverse for the 98, 98.5, 99 and 99.5 percent quantiles. However, the difference becomes smaller and the situation finally reverses for the 99.9 and 99.95 percent quantiles.

The above finding supports the statement that both leverage as well as volatility feedback may play a role in explaining extreme asymmetric volatility. This evidence is supported by the results of Table 7 , where we plot the estimated high-quantile exceedance probabilities for the symmetric logistic GPD model with lagged shocks. We choose the conditioning values as the 99 and 99.9 percent quantiles and then consider the conditional probabilities of large shocks in either series given a lagged large shock in the respective other series. As can be seen from the results, e.g., a volatility shock of 2.97 or higher and a subsequent return shock of -1.75 or smaller occurs with a probability of 2.69 percent. Such event would describe a lagged extreme volatility feedback event at the 99 percent exceedance level. As can further be seen from Table 7, leverage events appear with even higher probability. In sum, we again find that both hypothesis play a role in explaining volatility asymmetry. 


\subsubsection{Asset Pricing Implications of Extreme Volatility Feedback}

Given the above results, extreme asymmetric volatility is found to be a contemporaneous phenomenon that is related to both, the leverage and the feedback effect. As a consequence of the latter, we find that large unexpected shocks to implied market volatility may indeed affect market returns. In other words, there is a considerable chance that large negative market price shocks happen conditional on shocks to implied market volatility. As pointed out in Li (2004) and Engle and Mistry (2007) for example, such a possibility is consistent with results from intertemporal asset pricing models, once market volatility is a priced risk factor. In this section, we consider the empirical asset pricing implications of extreme volatility feedback in more detail. Given our results above, we address aggregate market price effects.

Extreme volatility feedback may have substantial asset pricing implications. Given an extreme volatility shock, a large negative return shock will occur with some given probability. In this case, the negative return shock has a given expectation, which is the "expected shortfall". Based on our model setting above, we can derive the asset pricing implications of extreme volatility shocks. More precisely, unexpected return and volatility shocks, $\left(-Y_{t}, Z_{t}\right)$, as defined above, allow us to derive the following:

- Given a large unexpected shock to implied market volatility, $Z_{t}$, which exceeds its $p$-percent quantile $z$, i.e. $Z_{t}>z$, we may face a negative market shock, $-Y_{t}$.

- With probability $P\left(-Y_{t}>-y \mid Z_{t}>z\right)=s$, extreme volatility feedback occurs: The negative market shock exceeds $-y$ and implies an expected negative market return, or "expected shortfall", of: $\mathbb{E}\left(-Y_{t} \mid-Y_{t}>-y\right)$.

- With probability $P\left(-Y_{t} \leq-y \mid Z_{t}>z\right)=1-s$, no extreme feedback occurs.

In order to derive asset pricing implications of extreme volatility feedback, we make the following assumptions:

- The given volatility shock, $Z_{t}>z$, exceeds one of the $p$-percent quantiles $z$ as given in Table 6 . The table also reports the corresponding feedback probability, $P\left(-Y_{t}>-y \mid Z_{t}>z\right)$, and the expected shortfall, $\mathbb{E}\left(-Y_{t} \mid-Y_{t}>\right.$ $-y)$. 
- Predictions are made based on our return-volatility model (2.1-2), where the volatility shock affects returns via an update in conditional volatility.

- We set the variables $\sigma_{t}$ and $\phi_{t}$ in equation (2.2) equal to their unconditional means. For $\sigma_{t}$, we start with an unconditional market volatility level of $\bar{\sigma}=0.0121$ (i.e. 19.1 percent on an annualized level) and then increase this level in several steps.

Figure 6 summarizes our empirical asset pricing results under extreme feedback. Given our setting above, the figure plots the estimated negative (percentage) market price impact under extreme volatility feedback. The results are calculated for the six volatility shock quantiles $z$ as given in Table 6 . The initial volatility level is set to 19.1 (the unconditional base level) and then increases to 22.5, 25, 27.5 and 30 percent, respectively.

The results in Figure 6 document that the asset pricing impact increases with the volatility shock size as well as with the market volatility level. Assuming, for example, a market volatility at its unconditional sample mean of 19.1 percent annually, an unexpected 3-sigma market volatility jump (which occurs in one out of one hundred trading days on average) has a feedback probability of a little less than 50 percent (see Table 6). Given that extreme feedback occurs, aggregate market prices are predicted to decline by about 2.5 percent. Our conditioning assumption is relatively conservative. Assuming, other things equal, an already highly volatile (i.e. stressed) market at an annualized implied volatility of 30 percent, prices are predicted to decline by about 4 percent. Figure 6 also indicates that the asset pricing effects of feedback tend to increase in the range of increasing quantiles of unexpected market volatility jumps. In sum, our findings can help to illustrate the quite tremendous aggregate market price effects, which single-day volatility shocks may have under volatility feedback.

\section{Conclusion}

How can we explain periods of market stress - i.e. large market downturns or crashes - when publicly available fundamental information does not seem to justify such market behavior? Various studies have addressed this question; see for example the empirical study by Haugen, Talmor, and Torous (1991). We bring 
new insight to this question by focusing on the extreme dependence between conditional market volatility and market returns. Given our results, extreme asymmetric volatility including volatility feedback at extreme levels is supposed to play an important role in explaining such equity market declines. Furthermore, our results suggest that large market declines can at least in parts be seen as a consequence of feedback and hence rational asset pricing behavior. The documented phenomenon of extreme asymmetric volatility clearly represents a component in the risk of market failure and therefore constitutes an important component of systemic risk. Regulation of financial institutions and markets aims at a control of such systemic risk. Given the debate on the necessity of various forms of regulation, it appears important to improve our understanding of the functioning of financial markets. Our findings, which support the existence of extreme volatility feedback, would therefore suggest that the stabilization of extreme conditional market volatility should in fact be an important task for market regulators.

Research on stock market volatility remains a challenging area. Bollerslev, Sizova and Tauchen (2008) derive and test an equilibrium model of stock market volatility, which captures many of the stylized empirical facts of volatility including asymmetry. Future research in the area may address the importance of conditional volatility jointly with additional state variables in the modeling and forecasting of periods of market stress. Future research may also give further empirical insights to the question of asset pricing under volatility feedback and to the question of mispriced out-of-the-money index options; see also for example Carr and Wu (2008). 


\section{References}

[1] Avramov D., Chordia T., Goyal A. (2006): The Impact of Trades on Daily Volatility, Review of Financial Studies 19: 1241-1277

[2] Aydemir A. C., Gallmeyer M., Hollifield B. (2006): Financial Leverage Does Not Cause the Leverage Effect, Working Paper, Texas A\&M University

[3] Bae J., Kim C.-J., Nelson C. R. (2007): Why are Stock Returns and Volatility Negatively Correlated?, Journal of Empirical Finance 14: 41-58

[4] Beirlant J., Goegebeur Y., Segers J., Teugels J. (2004): Statistics of Extremes: Theory and Applications, Wiley, Chichester

[5] Bekaert G., Wu G. (2000): Asymmetric Volatility and Risk in Equity Markets, Review of Financial Studies 13: 1-42

[6] Black F. (1976): Studies of Stock Price Volatility Changes, Proceedings of the American Statistical Association, Business and Economic Statistics Section, Chicago, pp. 177-181

[7] Bollerslev T., Chou R. Y., Kroner K. F. (1992): ARCH Modeling in Finance: A Review of the Theory and Empirical Evidence, Journal of Econometrics 52, 5-59

[8] Bollerslev T., Litvinova J., Tauchen G. (2006): Leverage and Volatility Feedback Effects in High-Frequency Data, Journal of Financial Econometrics 4: $353-384$

[9] Bollerslev T., Sizova N., Tauchen G. (2008): Volatility in Equilibrium: Asymmetries and Dynamic Dependencies, Working Paper, Duke University

[10] Bollerslev T., Wooldridge, J. M. (1992): Quasi-Maximum Likelihood Estimation and Inference in Dynamic Models with Time-Varying Covariances, Econometric Reviews 11: 143-172

[11] Campbell J. Y., Hentschel L. (1992): No News is Good News: An Asymmetric Model of Changing Volatility in Stock Returns, Journal of Financial Economics 31: 281-318 
[12] Carr P., Wu L. (2008): Leverage Effect, Volatility Feedback, and SelfExciting Market Disruptions: Disentangling the Multi-Dimensional Variations in S\&P 500 Index Options, Working Paper, City University of New York

[13] Chicago Board Options Exchange CBOE (2003): The New CBOE Volatility Index VIX, Chicago, September 2003

[14] Christie A. A. (1982): The Stochastic Behavior of Common Stock Variances: Value, Leverage and Interest Rate Effects, Journal of Financial Economics 10: 407-432

[15] Coles S. G. (2001): An Introduction to Statistical Modeling of Extreme Values, Springer, London

[16] Coles S. G., Heffernan J., Tawn J. (1999): Dependence Measures for Multivariate Extremes, Extremes 2: 339-365

[17] Diebold, F. X., Schuermann, T., Stroughair, J. D. (1998): Pitfalls and Opportunities in the Use of Extreme Value Theory in Risk Management, in: Refenes, A.-P. N., Burgess, A. N., Moody, J. E. (eds.): Decision Technologies for Computational Finance, Kluwer, Dordrecht, pp. 3-12

[18] Embrechts P., Klüppelberg C., Mikosch T. (1997): Modelling Extremal Events for Insurance and Finance, Springer, New York

[19] Engle R. F. (2002): Dynamic Conditional Correlation: A Simple Class of Multivariate Generalized Autoregressive Conditional Heteroskedasticity Models, Journal of Business and Economic Statistics 20: 339-350

[20] Engle R. F., Mistry A. (2007): Priced Risk and Asymmetric Volatility in the Cross-Section of Skewness, Working Paper, New York University

[21] Engle R. F., Ng V. K. (1993): Measuring and Testing the Impact of News on Volatility, Journal of Finance 48: 1749-1778

[22] Engle R. F., Sheppard K. (2001): Theoretical and Empirical Properties of Dynamic Conditional Correlation Multivariate GARCH, Working Paper, U.C. San Diego 
[23] Falk M., Michel R. (2006): Testing for Tail Independence in Extreme Value Models, Annals of the Institute of Statistical Mathematics 58: 261-290

[24] French K. R., Schwert G. W., Stambaugh R. F. (1987): Expected Returns and Volatility, Journal of Financial Economics 19: 3-29

[25] Glosten L. R., Jagannathan R., Runkle D. E. (1993): On the Relation between the Expected Value and the Volatility of the Nominal Excess Return on Stocks, Journal of Finance 48: 1779-1801

[26] Gumbel E. J. (1960): Bivariate Exponential Distributions, Journal of the American Statistical Association 55: 698-707

[27] Haugen, R. A., Talmor, E., Torous, W. N. (1991): The Effect of Volatility Changes on the Level of Subsequent Expected Returns, Journal of Finance 46: 985-1007

[28] Hibbert A. M., Daigler R. T., Dupoyet B. (2008): A Behavioral Explanation for the Negative Asymmetric Return-Volatility Relation, Journal of Banking and Finance 32: 2254-2266

[29] International Monetary Fund, IMF (2003): Financial Asset Price Volatility: A Source of Instability?, in: Global Financial Stability Report, September 2003, pp. 62-88

[30] Kim C.-J., Morley J. C., Nelson C. R. (2004): Is there a Positive Relationship between Stock Market Volatility and the Equity Premium?, Journal of Money, Credit, and Banking 36: 339-360

[31] Ledford A. W., Tawn J. A. (1996): Statistics for Near Independence in Multivariate Extreme Values, Biometrika 83: 169-187

[32] Li C. (2004): The Skewness Premium and the Asymmetric Volatility Puzzle, Working Paper, U.C. Riverside

[33] Longin F., Solnik B. (2001): Extreme Correlation of International Equity Markets, Journal of Finance 56: 649-676

[34] Marsh T. A., Wagner N. (2000): Return-Volume Dependence and Extremes in International Equity Markets, Working Paper No. RPF-293, U.C. Berkeley 
[35] Merton R. C. (1973): An Intertemporal Capital Asset Pricing Model, Econometrica 41: 867-887

[36] Merton R. C. (1980): On Estimating the Expected Return on the Market: An Exploratory Investigation, Journal of Financial Economics 8: 323-361

[37] Nelson D. B. (1991): Conditional Heteroskedasticity in Asset Returns: A New Approach, Econometrica 59: 347-370

[38] Pickands, J. (1981): Multivariate Extreme Value Distributions, Bulletin of the International Statistical Institute 69: 859-878

[39] Pindyck R. S. (1984): Risk, Inflation, and the Stock Market, American Economic Review 74: 334-351

[40] Poon S.-H., Rockinger M., Tawn J. A. (2004): Extreme Value Dependence in Financial Markets: Diagnostics, Models, and Financial Implications, Review of Financial Studies 17: 581-610

[41] Silvapulle P., Granger C. W. J. (2001): Large Returns, Conditional Correlation and Portfolio Diversification: A Value-at-Risk Approach, Quantitative Finance 1: 542-551

[42] Smith D. R. (2007): Risk and Return in Stochastic Volatility Models: Volatility Feedback Matters, Working Paper, Simon Fraser University

[43] Straetmans S. T. M., Verschoor W. F. C., Wolff C. C. P. (2008): Extreme US stock market fluctuations in the wake of 9/11, Journal of Applied Econometrics 23: 17-42

[44] Tawn J. A. (1988): Bivariate Extreme Value Theory: Models and Estimation, Biometrika 75: 397-415

[45] Todorov V., Tauchen G. (2008): Volatility Jumps, Working Paper, Duke University

[46] Wagner N., Marsh T. A. (2005): Surprise Volume and Heteroskedasticity in Equity Market Returns, Quantitative Finance 5: 153-168

[47] Whaley R. E. (2000): The Investor Fear Gauge, Journal of Portfolio Management 26: 12-17 
[48] Wu G. (2001): The Determinants of Asymmetric Volatility, Review of Financial Studies 14: 837-859

[49] Wu G., Xiao Z. (2002): A Generalized Partially Linear Model of Asymmetric Volatility, Journal of Empirical Finance 9: 287-319

[50] Zakoian, J.-M. (1994): Threshold Heteroskedastic Models, Journal of Economic Dynamics and Control 18: 931-955 


\section{Table 1: Descriptive Statistics}

Descriptive statistics for unexpected return and volatility shocks, $Y_{t}$ and $Z_{t}$. Ljung/Box $\mathrm{Q}(k)$-statistics at lag $k$ test for the null hypothesis of zero autocorrelation coefficients up to order $k$ in each of the original as well as squared series. GARCH-f1 denotes maximum likelihood estimation results for model (2.2-3) with $p=4$ and asymmetric specification $f_{1}$. Results are derived under the assumption of Student-t distributed volatility shocks $Z_{t}$ with an estimated number of degrees of freedom of 5.27 (standard error of 0.36) and a maximized log likelihood value of 7499.8. Given the model, Engle's ARCH LM $(k)$-statistic at lag $k=1,2$ and 3 is computed from an auxiliary test regression and tests the null hypothesis of no ARCH effects in the shocks $Z_{\mathrm{t}}$ up to order $k$. Sample period: January 2, 1990 to September 30, 2008.

\begin{tabular}{|c|c|c|c|c|}
\hline & $Y$ & $Z$ & Z: GARCH-f1 & \\
\hline Mean & 0.0265 & 0.0447 & $\begin{array}{c}\omega_{0} \\
\text { (t-value) }\end{array}$ & $\begin{array}{l}0.0000 \\
(0.043)\end{array}$ \\
\hline Median & -0.00850 & -0.0155 & $\begin{array}{c}\omega_{1} \\
\text { (t-value) }\end{array}$ & $\begin{array}{l}-0.142 \\
(-1.01)\end{array}$ \\
\hline Maximum & 3.52 & 10.04 & $\begin{array}{c}\omega_{2} \\
\text { (t-value) }\end{array}$ & $\begin{array}{l}-0.241 \\
(-1.19)\end{array}$ \\
\hline Minimum & -3.63 & -4.34 & $\begin{array}{c}\gamma_{0} \\
\text { (t-value) }\end{array}$ & $\begin{array}{c}0.0002 * * \\
(6.15)\end{array}$ \\
\hline Std. Dev. & 0.74 & 1.01 & $\begin{array}{c}\gamma_{1} \\
\text { (t-value) }\end{array}$ & $\begin{array}{c}0.120^{* * *} \\
(7.39)\end{array}$ \\
\hline Skewness & 0.0694 & 0.987 & $\begin{array}{c}\gamma_{2} \\
\text { (t-value) }\end{array}$ & $\begin{array}{c}-0.125^{* *} \\
(-6.60) \\
\end{array}$ \\
\hline Kurtosis & 3.79 & 9.01 & $\begin{array}{c}\gamma_{3} \\
\text { (t-value) }\end{array}$ & $\begin{array}{l}0.864 * * \\
(47.99)\end{array}$ \\
\hline $\begin{array}{l}\text { Q (1) original - (probability) } \\
\text { Q (1) squared - (probability) }\end{array}$ & $\begin{array}{l}1.918(0.17) \\
0.573(0.45)\end{array}$ & $\begin{array}{c}0.127(0.72) \\
0.0920(0.76)\end{array}$ & $\begin{array}{l}\text { Engle LM (1) } \\
\text { (probability) }\end{array}$ & $\begin{array}{l}0.0919 \\
(0.76)\end{array}$ \\
\hline $\begin{array}{l}\text { Q (2) original - (probability) } \\
\text { Q (2) squared - (probability) }\end{array}$ & $\begin{array}{l}5.367(0.068) \\
5.859(0.053)\end{array}$ & $\begin{array}{l}0.190(0.91) \\
0.426(0.81)\end{array}$ & $\begin{array}{l}\text { Engle LM (2) } \\
\text { (probability) }\end{array}$ & $\begin{array}{l}0.428 \\
(0.81)\end{array}$ \\
\hline $\begin{array}{l}\text { Q (3) original - (probability) } \\
Q(3) \text { squared - (probability) }\end{array}$ & $\begin{array}{c}9.910^{*}(0.019) \\
11.955^{* *}(0.008)\end{array}$ & $\begin{array}{l}0.532(0.91) \\
0.445(0.93)\end{array}$ & $\begin{array}{c}\text { Engle LM (3) } \\
\text { (probability) }\end{array}$ & $\begin{array}{l}0.446 \\
(0.93)\end{array}$ \\
\hline
\end{tabular}

$*$ denotes significance for a double-sided test at the $95 \%$ confidence level, $* *$ denotes significance for a double-sided test at the $99 \%$ confidence level. 


\section{Table 2: Estimates of the Dynamic Conditional Correlation Model}

Maximum likelihood parameter estimates of the Dynamic Conditional Correlation (DCC) between unexpected return and volatility shocks, $Y_{t}$ and $Z_{t}$. The asymptotic mean test is based on the hypothesis that mean conditional correlation is equal to zero, the asymptotic variance test is based on the hypothesis that the variance of conditional correlation is equal to zero. The Jarque-Bera normality test is based on the null hypothesis that conditional correlation is normally distributed. Pearson's correlation test is based on the hypothesis that unconditional correlation is zero. Sample period: January 2, 1990 to September 30, 2008.

\begin{tabular}{|c|c|c|c|}
\hline Dynamic Conditional Correlation & $v_{1}$ & $v_{2}$ & $\log L$ \\
\hline \multirow[t]{2}{*}{$\begin{array}{l}\text { Parameter estimate } \\
\text { (standard error) }\end{array}$} & $\begin{array}{l}0.0158 * * \\
(0.00188)\end{array}$ & $\begin{array}{l}0.980 * * \\
(0.00280)\end{array}$ & 3188.1 \\
\hline & $\mathrm{H}_{0}:$ Mean $=0$ & $\mathrm{H}_{0}: \operatorname{Var}=0$ & Jarque-Bera \\
\hline $\begin{array}{l}\text { Test statistic } \\
\text { (p-value) }\end{array}$ & $\begin{array}{l}-418.3 \\
(0.000)\end{array}$ & $\begin{array}{c}51.9 \\
(0.000)\end{array}$ & $\begin{array}{l}480.8 \\
(0.000)\end{array}$ \\
\hline Unconditional Correlation & & & \\
\hline $\begin{array}{c}\text { Parameter estimates } \\
\quad(\mathrm{t} \text {-statistic) }\end{array}$ & $\begin{array}{l}-0.689 \\
(-66.48)\end{array}$ & -0.674 & -0.704 \\
\hline
\end{tabular}

** denotes significance for a double-sided test at the $99 \%$ confidence level. 


\section{Table 3: Threshold Choice}

Guidance from three different threshold choice approaches for the upper and lower tail of the return and volatility shocks, $Y_{t}$ and $Z_{t}$. MEF denotes graphical inspection of the mean excess plot and selection of a value beyond which the plot is approximately linear. The threshold plot method displays the resulting tail index estimates as a function of the chosen threshold. The given intervals denote the range of threshold choices for which the resulting tail estimates appear reasonably stable. Visual selection denotes a plausible threshold choice based on the results of the two given plot methods. Adaptive selection denotes the application of an automated method which aims at minimizing asymptotic mean squared error (see Beirlant et al. (2004), Section 4.7 ii). Sample period: January 2, 1990 to September 30, 2008.

\begin{tabular}{ccccc} 
& $Y$ & $-Y$ & $Z$ & $-Z$ \\
\hline MEF plot & 1.5 & 1.5 & 1.5 & 1.0 \\
\hline Threshold plot & {$[0.2,1.5]$} & {$[1.0,1.5]$} & {$[1.5,2.5]$} & 1.5 \\
\hline Visual selection & 1.5 & 1.2 & 1.5 & $1.5]$ \\
\hline Adaptive selection & $0.7^{*}$ & $1.4^{*}$ & $1.6^{*}$ & $0.7^{*}$ \\
\hline
\end{tabular}

* denotes the chosen threshold value for model estimation and further calculations. 


\section{Table 4: Marginal Parameter Estimates for the GPD Model}

Maximum likelihood estimates of the marginal GPD model parameters according to Ledford and Tawn (1996) given the threshold choice of Table 3. Estimated standard errors are given in parenthesis. '\#' denotes the number of marginal tail observations. $\log L$ is the negative logarithmic likelihood as evaluated at the parameter estimates, which are obtained via the Broyden-Fletcher-Goldfarb-Shanno method. Sample period: January 2, 1990 to September 30, 2008.

\begin{tabular}{|c|c|c|c|c|}
\hline & Y & $-Y$ & $Z$ & $-Z$ \\
\hline$\xi$ & $\begin{array}{l}-0.131 * \\
(0.0266) \\
\end{array}$ & $\begin{array}{c}0.0170 \\
(0.0849)\end{array}$ & $\begin{array}{c}0.218^{*} \\
(0.0670) \\
\end{array}$ & $\begin{array}{l}-0.0842 * \\
(0.0264) \\
\end{array}$ \\
\hline$\beta$ & $\begin{array}{c}0.523 * \\
(0.0230) \\
\end{array}$ & $\begin{array}{c}0.359^{*} \\
(0.0441) \\
\end{array}$ & $\begin{array}{c}0.590^{*} \\
(0.0517) \\
\end{array}$ & $\begin{array}{c}0.565 * \\
(0.0233) \\
\end{array}$ \\
\hline Threshold & 0.7 & 1.4 & 1.6 & 0.7 \\
\hline$\#$ & 805 & 127 & 301 & 992 \\
\hline $\log L$ & 178.0 & -0.8 & 207.9 & 342.8 \\
\hline
\end{tabular}

* denotes parameter significantly different from zero at he $95 \%$ confidence level. 


\section{Table 5: Dependence Estimates for the GPD Model}

Maximum likelihood estimates of the symmetric and the asymmetric logistic GPD model dependence parameters according to Ledford and Tawn (1996) given the threshold choice of Table 3. Estimated standard errors are given in parenthesis. '\#joint' denotes the number of joint tail observations. $\log L$ is the negative $\log$ likelihood as evaluated at the parameter estimates, which are obtained via the Broyden-FletcherGoldfarb-Shanno method. Sample period: January 2, 1990 to September 30, 2008.

\begin{tabular}{|c|c|c|}
\hline & $\begin{array}{c}\text { «crash» } \\
(-Y, Z)\end{array}$ & $\begin{array}{c}\text { «boom» } \\
(Y,-Z)\end{array}$ \\
\hline \multicolumn{3}{|l|}{ Logistic } \\
\hline$\chi$ & 0.484 & 0.419 \\
\hline$\alpha$ & $\begin{array}{c}0.601 * \\
(0.0279) \\
\end{array}$ & $\begin{array}{c}0.661^{*} \\
(0.0137) \\
\end{array}$ \\
\hline AIC & 3392.97 & 9484.97 \\
\hline \multicolumn{3}{|c|}{ Asymmetric Logistic } \\
\hline$\chi$ & 0.427 & 0.439 \\
\hline$\alpha$ & $\begin{array}{c}0.631^{*} \\
(0.0330) \\
\end{array}$ & $\begin{array}{c}0.633^{*} \\
(0.0231) \\
\end{array}$ \\
\hline$\theta_{1}$ & $\begin{array}{c}0.999 \\
(0.000) \\
\end{array}$ & $\begin{array}{c}0.955 \\
(0.0755)\end{array}$ \\
\hline$\theta_{2}$ & $\begin{array}{c}.89799 \\
(0.117) \\
\end{array}$ & $\begin{array}{c}0.999 \\
(0.000) \\
\end{array}$ \\
\hline AIC & 3400.96 & 9498.54 \\
\hline Threshold & $(1.4,1.6)$ & $(0.7,0.7)$ \\
\hline \# joint & 91 & 475 \\
\hline
\end{tabular}

* denotes parameter significantly different from one at the $95 \%$ confidence level. 


\section{Table 6: High Quantile Exceedance Probabilities}

Estimated high-quantile exceedance probabilities for the symmetric logistic GPD model (threshold choice of Table 3). We consider the «crash» scenario, i.e. $(-Y, Z)$, for which the model is shown to be valid. The conditioning values are chosen as the $98 \%, 98.5 \%, 99 \%, 99.5 \%, 99.9 \%$ and 99.95\% quantiles, respectively. Given are the corresponding marginal exceedance probabilities. Reported are joint as well as conditional exceedance probabilities, the latter allowing to distinguish between intradaily leverage versus feedback causality. Expected marginal shortfall with 95\% confidence interval in parenthesis is given for the return shocks. Sample period: January 2, 1990 to September 30, 2008.

\begin{tabular}{|c|c|c|c|c|c|c|}
\hline $\begin{array}{l}\text { quantile and corresponding } \\
\text { conditioning values, }(y, z) \text {, } \\
\text { where } y>1.4 \text { and } z>1.6\end{array}$ & $\begin{array}{l}98 \% \text { quantile } \\
(1.49,2.39)\end{array}$ & $\begin{array}{c}98.5 \% \text { quantile } \\
(1.60,2.62)\end{array}$ & $\begin{array}{c}99 \% \text { quantile } \\
(1.75,2.97)\end{array}$ & $\begin{array}{c}99.5 \% \text { quantile } \\
(2.00,3.61)\end{array}$ & $\begin{array}{l}99.9 \% \text { quantile } \\
(2.60,5.40)\end{array}$ & $\begin{array}{c}99.95 \% \text { quantile } \\
(2.87,6.32)\end{array}$ \\
\hline $\mathrm{P}(-Y>-y)$ & $2.00 \%$ & $1.50 \%$ & $1.00 \%$ & $0.50 \%$ & $0.10 \%$ & $0.05 \%$ \\
\hline $\mathrm{P}(Z>z)$ & $1.91 \%$ & $1.42 \%$ & $0.94 \%$ & $0.48 \%$ & $0.11 \%$ & $0.06 \%$ \\
\hline $\mathrm{P}(-Y>-y, Z>z)$ & $0.94 \%$ & $0.71 \%$ & $0.47 \%$ & $0.24 \%$ & $0.051 \%$ & $0.026 \%$ \\
\hline Leverage: $\mathrm{P}(Z>z \mid-Y>-y)$ & $47.2 \%$ & $47.0 \%$ & $46.9 \%$ & $47.4 \%$ & $50.6 \%$ & $52.7 \%$ \\
\hline Feedback: $\mathrm{P}(-Y>-y \mid Z>z)$ & $49.5 \%$ & $49.7 \%$ & $49.7 \%$ & $49.2 \%$ & $46.0 \%$ & $44.0 \%$ \\
\hline Expected Shortfall: $E(-Y \mid-Y>-y)$ & $\begin{array}{c}1.86 \\
(1.79 ; 1.96)\end{array}$ & $\begin{array}{c}1.97 \\
(1.88 ; 2.09)\end{array}$ & $\begin{array}{c}2.12 \\
(2.00 ; 2.29)\end{array}$ & $\begin{array}{c}2.38 \\
(2.22 ; 2.66)\end{array}$ & $\begin{array}{c}2.99 \\
(2.68 ; 3.75)\end{array}$ & $\begin{array}{c}3.26 \\
(2.86 ; 4.35)\end{array}$ \\
\hline
\end{tabular}




\section{Table 7: High Quantile Exceedance Probabilities with Lagged Shocks}

Estimated high-quantile exceedance probabilities for the symmetric logistic GPD model with lagged shocks (threshold choice of Table 3). The conditioning values are chosen as the $99 \%$ and $99.9 \%$ quantiles. Reported are corresponding marginal, joint as well as conditional exceedance probabilities. Lagged values allow to distinguish between leverage versus feedback causality. Sample period: January 2, 1990 to September 30 , 2008 .

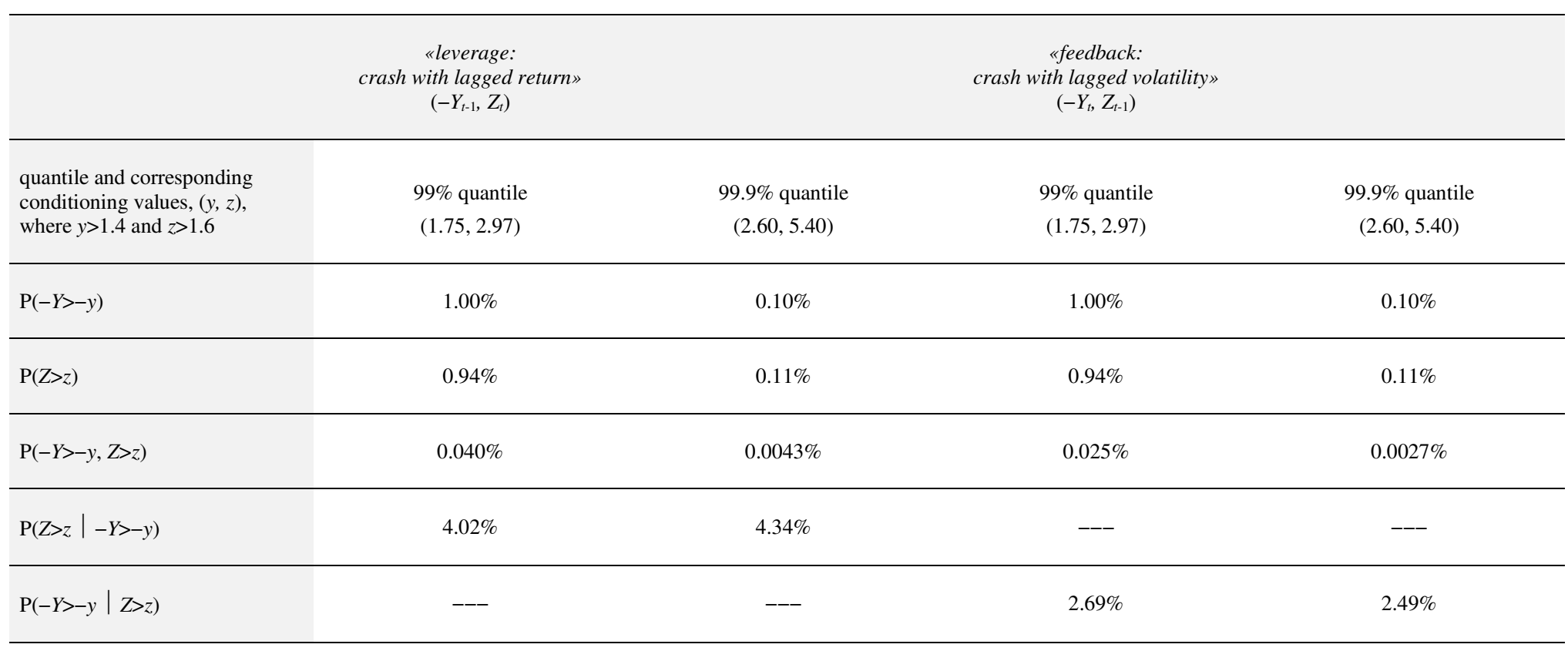




\section{Figure 1: Market Returns, Volatility and Volatility of Volatility}

Daily S\&P 500 index market returns (SPX), conditional VIX market volatility (VIX) and estimated conditional volatility of logarithmic VIX volatility, in short denoted as "conditional volatility of volatility" (VOV). VOV is based on an estimation of the ARCH model (2.2) for logarithmic VIX conditional market volatility with threshold specification $f_{1}$, Student-t distributed errors and variance equation (2.3). Sample period: January 2, 1990 to September 30, 2008.

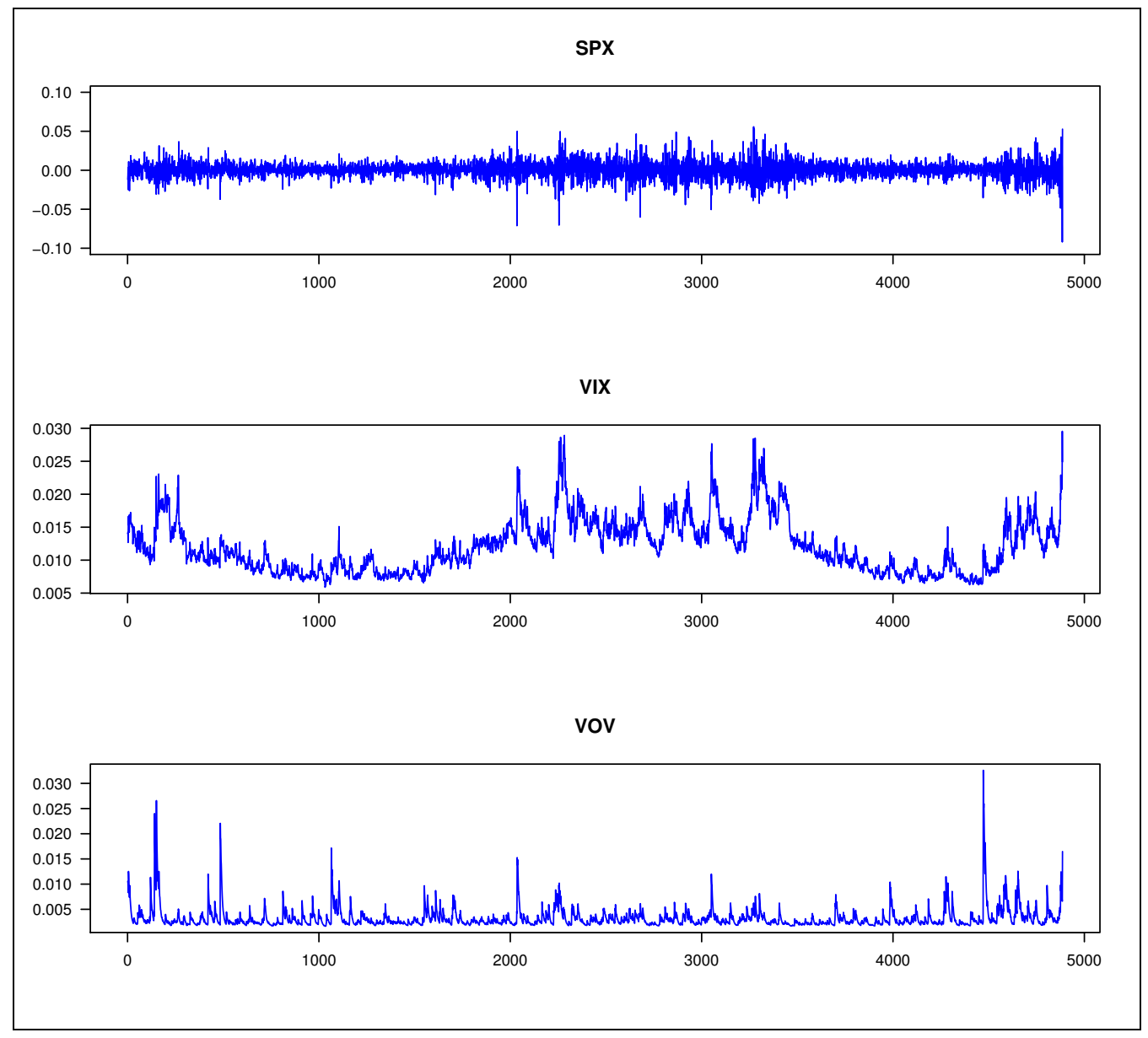


Figure 2: VIX and Conditional Correlation between Return and Volatility Shocks

Daily conditional VIX market volatility (VIX) and dynamic conditional correlation (DCC) estimates of the correlation between S\&P 500 index return shocks and VIX volatility shocks. Sample period: January 2, 1990 to September 30, 2008.

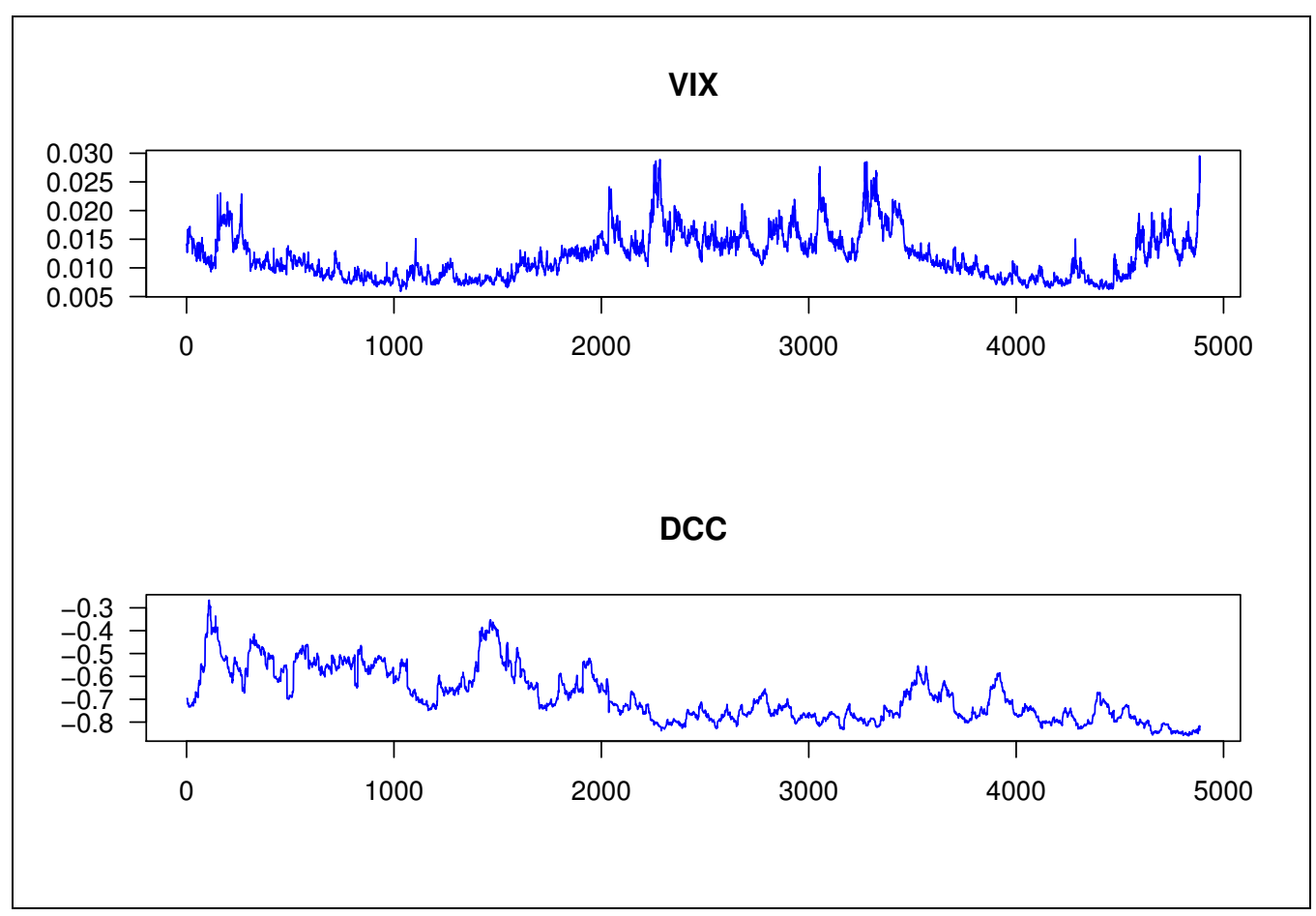




\section{Figure 3: Mean Excess Function Plots for Return and Volatility Shocks}

Mean excess function plots for daily S\&P 500 index return shocks, $Y$, and VIX volatility shocks, $Z$. Large unexpected markets increases, $Y$, jointly with volatility decreases, $-Z$, are denoted as 'boom'. Large unexpected markets decreases, $-Y$, jointly with volatility increases, $Z$, are denoted as 'crash'. Sample period: January 2, 1990 to September 30, 2008.

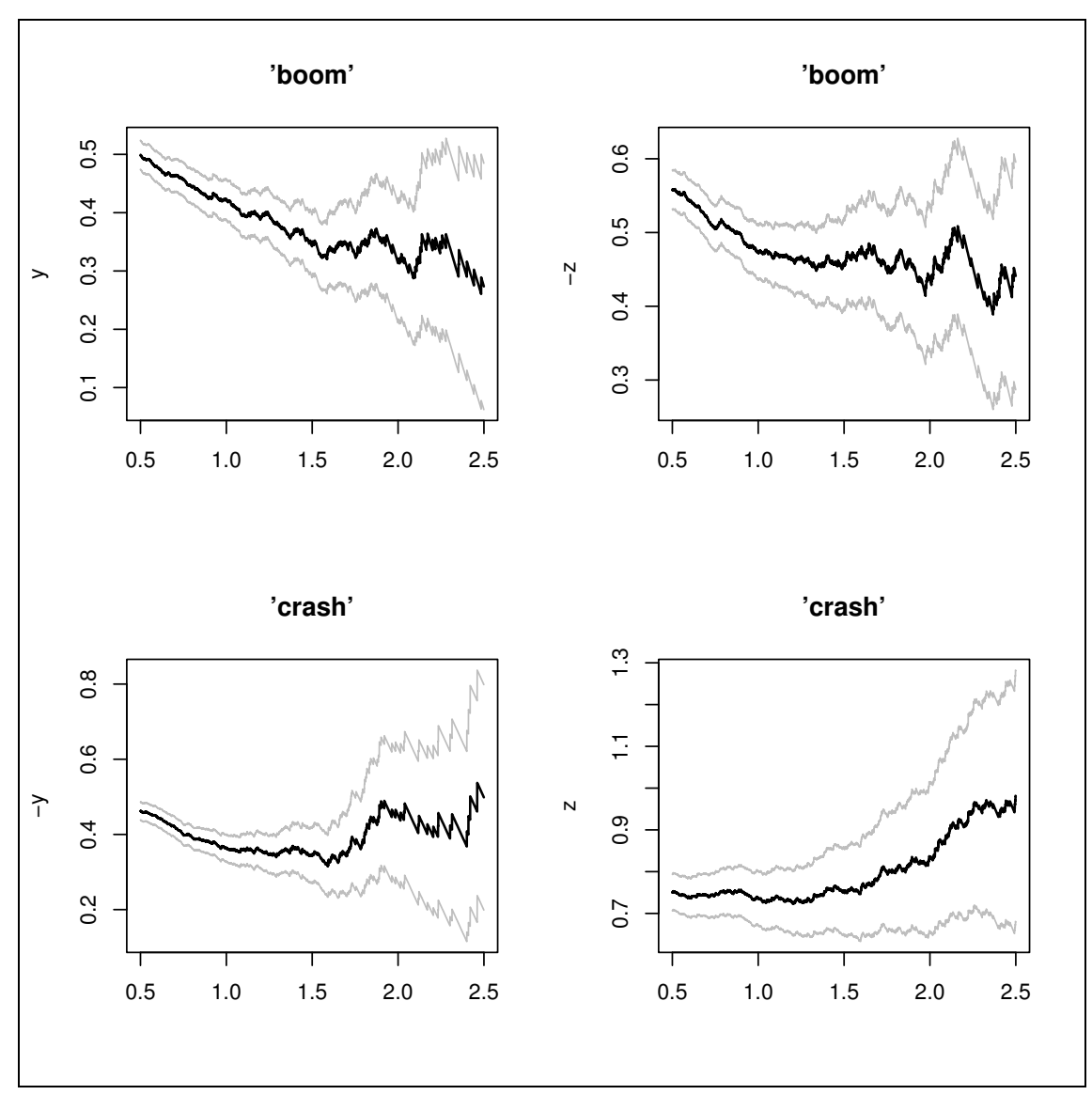




\section{Figure 4: Chi and Chi Bar Dependence Plots for Return and Volatility Shocks}

Chi and Chi Bar dependence plots for daily S\&P 500 index return shocks, $Y$, and VIX volatility shocks, $Z$. Large unexpected markets increases, $Y$, jointly with volatility decreases, $-Z$, are denoted as 'boom'. Large unexpected markets decreases, $-Y$, jointly with volatility increases, $Z$, are denoted as 'crash'. Sample period: January 2, 1990 to September 30, 2008.

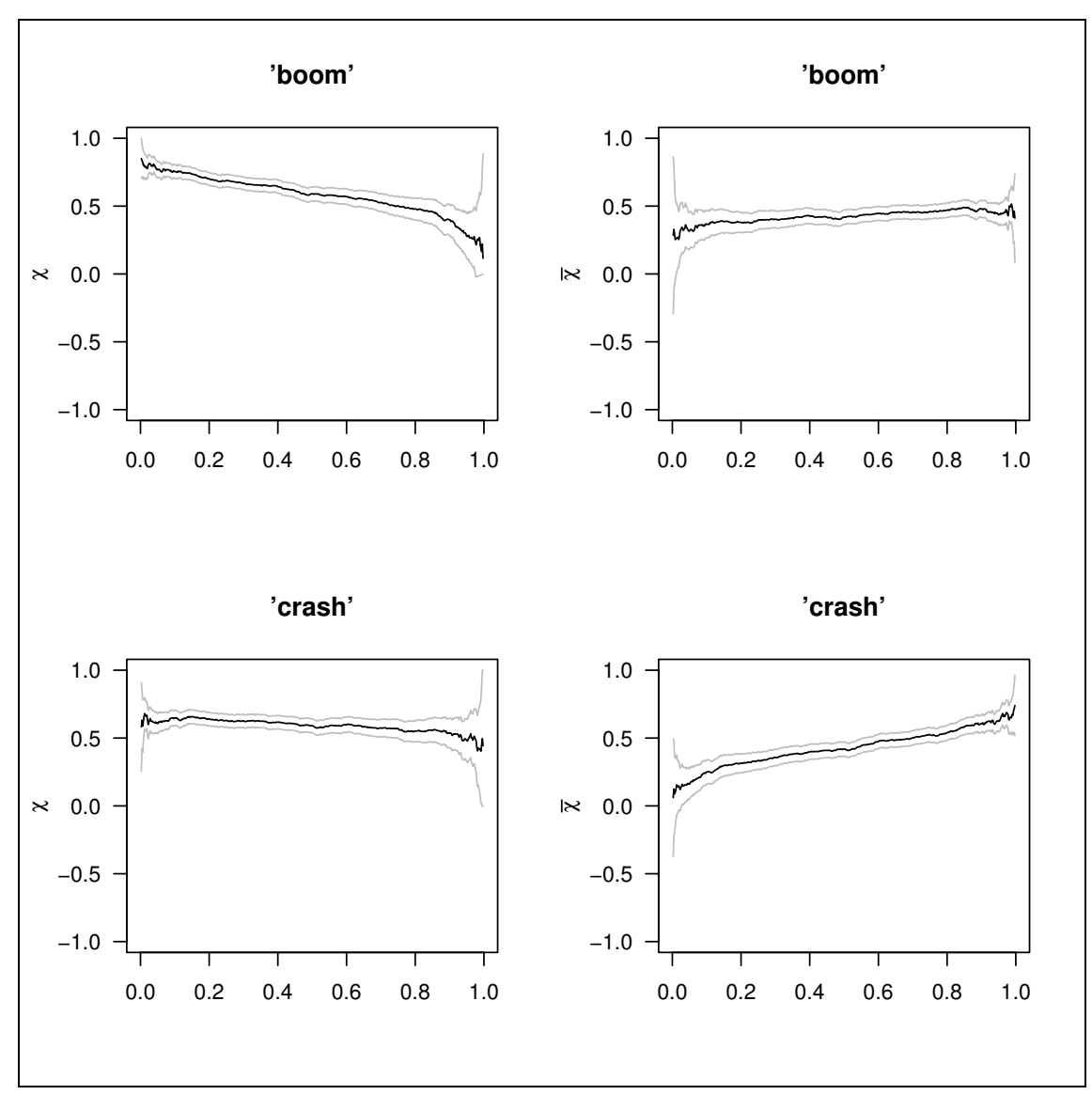




\section{Figure 5: Contour Plot for Large Market Declines in the Symmetric Threshold Model}

The figure plots daily realized negative S\&P 500 index return shocks, $-y$, and VIX volatility shocks, $z$, together with the marginal threshold for each series under the visual threshold choice of Table 3 , where $u_{-y}=1.2$ and $u_{z}=1.5$. Joint exceedances of the thresholds occur with an empirical probability of 3.21 percent. Sample period: January 2, 1990 to September 30, 2008.

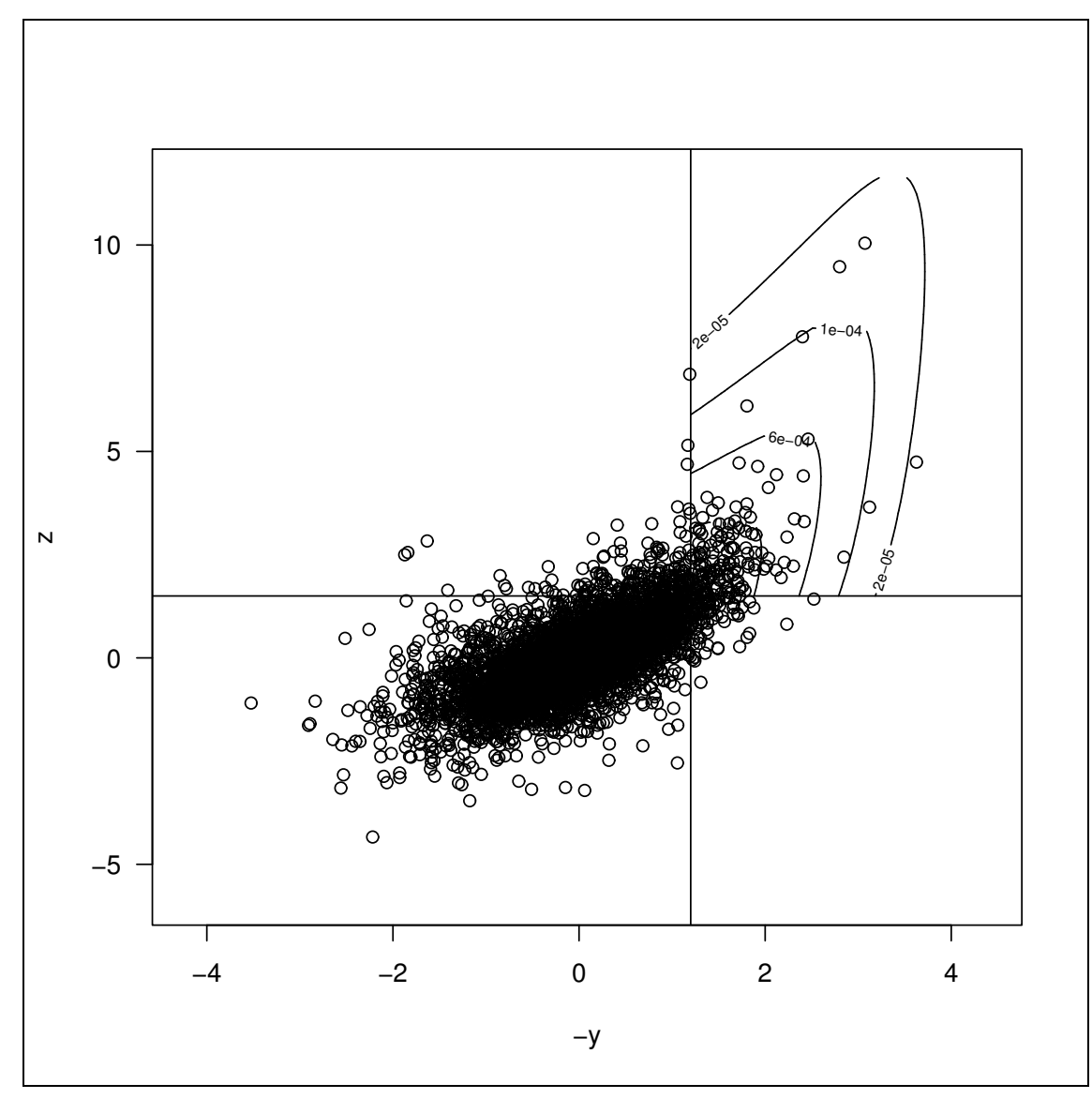




\section{Figure 6: Negative Market Price Impacts under Extreme Volatility Feedback}

The figure plots estimated daily negative S\&P 500 market price impacts under the occurrence of extreme volatility feedback. Initial volatility shocks, $Z>z$, exceed the given $98,98.5,99,99.5,99.9$ and 99.95 percent quantiles $z$, respectively (see Table 6). For each impact curve, the initial implied market volatility is set to an annual percentage level of 19.1 (unconditional level of implied volatility), $22.5,25,27.5$ and 30 , respectively. Sample period: January 2, 1990 to September 30, 2008.

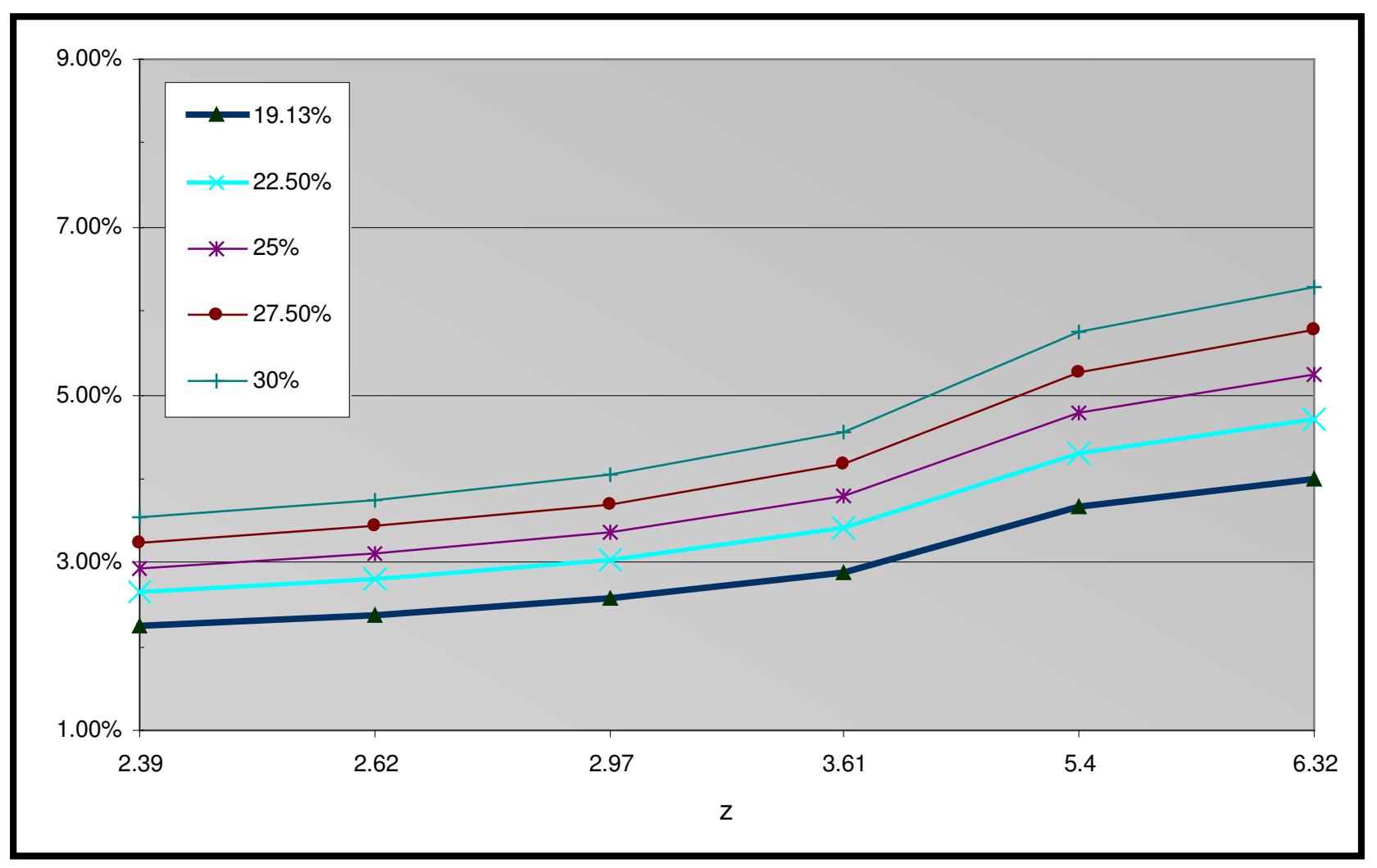

